\title{
Testosterone treatment is associated with reduced adipose tissue dysfunction and nonalcoholic fatty liver disease in obese hypogonadal men
}

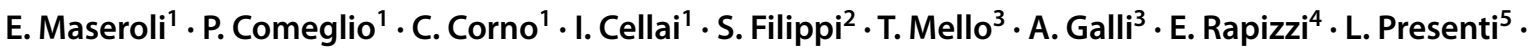 \\ M. C. Truglia ${ }^{5} \cdot$ F. Lotti ${ }^{1} \cdot$ E. Facchiano ${ }^{5} \cdot$ B. Beltrame ${ }^{5} \cdot$ M. Lucchese $^{5} \cdot$ F. Saad $^{6} \cdot$ G. Rastrelli $^{1} \cdot$ M. Maggi $^{4,7}$. \\ L. Vignozzi ${ }^{1,7}$
}

Received: 23 March 2020 / Accepted: 31 July 2020 / Published online: 8 August 2020

(c) The Author(s) 2020

\begin{abstract}
Purpose In both preclinical and clinical settings, testosterone treatment (TTh) of hypogonadism has shown beneficial effects on insulin sensitivity and visceral and liver fat accumulation. This prospective, observational study was aimed at assessing the change in markers of fat and liver functioning in obese men scheduled for bariatric surgery.

Methods Hypogonadal patients with consistent symptoms $(n=15)$ undergoing $27.63 \pm 3.64$ weeks of TTh were compared to untreated eugonadal $(n=17)$ or asymptomatic hypogonadal $(n=46)$ men. A cross-sectional analysis among the different groups was also performed, especially for data derived from liver and fat biopsies. Preadipocytes isolated from adipose tissue biopsies were used to evaluate insulin sensitivity, adipogenic potential and mitochondrial function. NAFLD was evaluated by triglyceride assay and by calculating NAFLD activity score in liver biopsies.

Results In TTh-hypogonadal men, histopathological NAFLD activity and steatosis scores, as well as liver triglyceride content were lower than in untreated-hypogonadal men and comparable to eugonadal ones. TTh was also associated with a favorable hepatic expression of lipid handling-related genes. In visceral adipose tissue and preadipocytes, TTh was associated with an increased expression of lipid catabolism and mitochondrial bio-functionality markers. Preadipocytes from TTh men also exhibited a healthier morpho-functional phenotype of mitochondria and higher insulin-sensitivity compared to untreated-hypogonadal ones.

Conclusions The present data suggest that TTh in severely obese, hypogonadal individuals induces metabolically healthier preadipocytes, improving insulin sensitivity, mitochondrial functioning and lipid handling. A potentially protective role for testosterone on the progression of NAFLD, improving hepatic steatosis and reducing intrahepatic triglyceride content, was also envisaged.
\end{abstract}

Clinical Trial Registration ClinicalTrials.gov Identifier: NCT02248467, September 25th 2014

Keywords Testosterone $\cdot$ Adipose tissue $\cdot$ Liver $\cdot$ NAFLD $\cdot$ Obesity $\cdot$ Hypogonadism

L. Vignozzi

linda.vignozzi@unifi.it

1 Andrology, Women's Endocrinology and Gender Incongruence Unit, Department of Experimental Clinical and Biomedical Sciences "Mario Serio", University of Florence, Viale Pieraccini 6, 50134 Florence, Italy

2 Interdepartmental Laboratory of Functional and Cellular Pharmacology of Reproduction, University of Florence, Viale Pieraccini 6, 50134 Florence, Italy

3 Gastroenterology Unit, Department of Experimental Clinical and Biomedical Sciences "Mario Serio", University of Florence, Viale Pieraccini 6, 50134 Florence, Italy
4 Endocrinology Unit, Department of Experimental Clinical and Biomedical Sciences "Mario Serio", University of Florence, Viale Pieraccini 6, 50134 Florence, Italy

5 General, Bariatric and Metabolic Surgery Unit, Santa Maria Nuova Hospital, , Piazza Santa Maria Nuova, 1, 50122 Florence, Italy

6 Medical Affairs, Bayer AG, Kaiser-Wilhelm-Allee 1, 51373 Leverkusen, Germany

7 I.N.B.B. (Istituto Nazionale Biostrutture E Biosistemi), Viale delle Medaglie d'Oro 305, 00136 Rome, Italy 


\section{Introduction}

Obesity, in particular abdominal obesity, is currently one of the greatest public health issues worldwide, owing to its high prevalence and substantial morbidity and mortality. The functional abnormalities of adipocytes, more than the excess of adipose mass itself, represent the major pathogenic link between obesity and non-transmittable chronic diseases, including type 2 diabetes, metabolic syndrome (MetS) and non-alcoholic fatty liver disease (NAFLD), which are all associated, to different degrees, with an increased risk of cardiovascular disease (CVD).

In obesity, excessive calorie intake finally often leads to an impaired insulin signaling, adipocyte hypertrophy, and lipid handling resistance [1-4]. In particular, the increased lipolysis from adipose tissue promotes hepatic insulin resistance by over-activation of hepatic gluconeogenesis and de novo lipid synthesis with a parallel deterioration of fatty acid oxidation. One of the primary mechanisms responsible for insulin resistance is the dysfunction of the main cellular organelles dedicated to metabolic control, i.e. mitochondria [5, 6]. Indeed, in adipocyte, dysfunctional mitochondria causes the spillover of lipids into nonadipose tissues, thus contributing to insulin resistance via lipotoxicity in other districts, including liver and vascular beds [7-10]. Therefore, these pathogenic mechanisms crucially link obesity to NAFLD and cardio-metabolic disorders $[8,11,12]$. Noteworthy, NAFLD is nowadays considered as a multisystem disease, affecting extra-hepatic organs and regulatory pathways, therefore amplifying the risk of type 2 diabetes mellitus (T2DM), cardiovascular (CVD) and cardiac diseases [13, 14].

Adding a layer of complexity, MetS and visceral obesity are also strongly associated with the onset of hypogonadotropic hypogonadism in males [15-17], due to functional abnormalities in the hypothalamus. Preclinical animal models demonstrated that MetS-induced hypogonadotropic hypogonadism is associated with a hypothalamic metainflammation, and with a substantial reduction of GnRH neurons [18, 19]. On the other hand, existing evidence consistently shows that testosterone therapy (TTh) induces a beneficial effect on metabolic parameters. In particular, several randomized [20-24] and observational $[25,26]$ trials demonstrated that TTh is able to improve body composition [27] and insulin sensitivity [20]. In an experimental rabbit model of high fat diet-induced MetS, our group previously demonstrated that in vivo $\mathrm{T}$ dosing prevented visceral adipose tissue (VAT) expansion [18, 28] and counteracted its derangements, normalizing preadipocyte maturation, lipid handling and insulin sensitivity [29]. In the same animal model, in vivo T dosing was also effective in counteracting all NAFLD features induced by
MetS, such as lipid accumulation, inflammation and initial fibrosis within the liver [29]. This is in keeping with other preclinical studies in animal models [30]. Finally, corroborating preclinical evidence indicated that testosterone treatment exerts beneficial metabolic effects mainly by improving MetS-related liver and adipose tissue dysfunctions [29, 31]. In humans, the ameliorating effects of androgens on MetS-associated adipose tissue and liver disease is supported by limited data [32, 33]. Therefore, perhaps surprisingly, the mechanism underlying how TTh improves whole-metabolic control was still missing. To further ascertain the effect of TTh on visceral adipose tissue and liver in a human setting, we designed an observational, prospective study enrolling severely obese male subjects on a waiting list to undergo bariatric surgery and stratified them, at baseline, as having $\mathrm{T}$ above (eugonadal) or below (hypogonadal) the normal value. A subgroup of hypogonadal subjects that also presented sexual symptoms were treated with TTh, according to guidelines, during the period before the surgical procedure. Therefore, our study design allows us to investigate the effect of in vivo TTh on VAT and liver dysfunction in obese hypogonadal men undergoing surgery for weight loss, as compared to untreated hypogonadal and eugonadal subjects. The assessment of the main morpho-functional features of human VAT preadipocytes, isolated from the three different treatment groups, was then performed, through analysis of glucose uptake, mitochondrial morphology and mRNA expression. We also studied the effect of TTh by evaluating morphological alterations and mRNA expression profiles of major pathogenic pathways related to NAFLD. These results are part of an observational study aimed at evaluating the effect of TTh on different complications of obesity in a population of severely obese men, candidates for bariatric surgery for weight loss.

\section{Methods}

Experimental procedures were carried out using the facilities of the Molecular Medicine Facility, Department of Biomedical Experimental and Clinical Sciences "Mario Serio", University of Florence.

\section{Study design}

This paper reports the results of the secondary analyses of an observational prospective study enrolling 78 severely obese men with indication for bariatric surgery. Table 1 reports the STROBE checklist showing compliance with guidelines. The study protocol was in accordance with the Declaration of Helsinki and was approved by the local ethics committee (protocol 2013/0006753; Careggi Hospital, Florence, Italy) 
Table 1 STROBE statement—checklist

\begin{tabular}{|c|c|c|}
\hline & Item no & Recommendation \\
\hline \multirow[t]{2}{*}{ Title and abstract } & 1 & $\begin{array}{l}\text { (a) Indicate the study's design with a commonly used term in the title or the abstract } \\
\text { The abstract describes the study design as "an observational, prospective study" }\end{array}$ \\
\hline & & $\begin{array}{l}\text { (b) Provide in the abstract an informative and balanced summary of what was done and what was found } \\
\text { The abstract describes the methods and findings }\end{array}$ \\
\hline \multicolumn{3}{|l|}{ Introduction } \\
\hline Background/rationale & 2 & $\begin{array}{l}\text { Explain the scientific background and rationale for the investigation being reported } \\
\text { The background and rationale are described in the Introduction, pages } 3 \& 4\end{array}$ \\
\hline Objectives & 3 & $\begin{array}{l}\text { State specific objectives, including any prespecified hypotheses } \\
\text { The specific aims of the study are stated in the last } 2 \text { paragraphs of the Introduction, page } 4\end{array}$ \\
\hline \multicolumn{3}{|l|}{ Methods } \\
\hline Study design & 4 & $\begin{array}{l}\text { Present key elements of study design early in the paper } \\
\text { The study design is discussed in the Introduction and in the "Study design and treatment" paragraph of } \\
\text { the Methods section }\end{array}$ \\
\hline Setting & 5 & $\begin{array}{l}\text { Describe the setting, locations, and relevant dates, including periods of recruitment, exposure, follow-up, } \\
\text { and data collection } \\
\text { The institutional setting, study locations are described and study timing is discussed in the "Study design } \\
\text { and treatment" paragraph of the Methods section }\end{array}$ \\
\hline Participants & 6 & $\begin{array}{l}\text { (a) Give the eligibility criteria, and the sources and methods of selection of participants. Describe meth- } \\
\text { ods of follow-up } \\
\text { Selection of the sample is discussed in the "Study design and treatment" paragraph of the Methods sec- } \\
\text { tion } \\
\text { (b) For matched studies, give matching criteria and number of exposed and unexposed } \\
\text { N/A }\end{array}$ \\
\hline Variables & 7 & $\begin{array}{l}\text { Clearly define all outcomes, exposures, predictors, potential confounders, and effect modifiers. Give } \\
\text { diagnostic criteria, if applicable } \\
\text { Outcomes, exposures, predictors etc. are discussed in the "Clinical parameters", "Biochemical, meta- } \\
\text { bolic and histological analyses", "Isolation, characterization and differentiation of human visceral fat } \\
\text { preadipocytes", "Glucose uptake", "RNA extraction and quantitative RT-PCR analysis", "Fluorescence } \\
\text { microscopy", "Oxygen consumption analysis" and "Statistical analysis" paragraphs of the Methods } \\
\text { section. The primary outcome of the clinical study was to evaluate the effect of TTh (Testosterone } \\
\text { Therapy) on LUTS (Lower Urinary Tract Symptoms) in severely obese men with moderate to severe } \\
\text { urinary symptoms, as evaluated by the International Prostate Symptom Score (IPSS) questionnaire; } \\
\text { however, this and other secondary clinical outcomes are not reported in the manuscript and will be } \\
\text { described in future publications. The outcomes reported in the present manuscript were changes over } \\
\text { time between and within HYPO and HYPO+ TTh groups in insulin sensitivity, adipogenic potential } \\
\text { and mitochondrial function of preadipocytes (hPADs) isolated from adipose tissue biopsies and in the } \\
\text { severity of NAFLD evaluated by triglycerides assay and liver biopsies histology }\end{array}$ \\
\hline Data sources/measurement & $8^{*}$ & $\begin{array}{l}\text { For each variable of interest, give sources of data and details of methods of assessment (measurement). } \\
\text { Describe comparability of assessment methods if there is more than one group } \\
\text { Measurement of the outcomes are discussed in the "Clinical parameters", "Biochemical, metabolic and } \\
\text { histological analyses", "Isolation, characterization and differentiation of human visceral fat preadipo- } \\
\text { cytes", "Glucose uptake", "RNA extraction and quantitative RT-PCR analysis", "Fluorescence micros- } \\
\text { copy", "Oxygen consumption analysis" and "Statistical analysis" paragraphs of the Methods section }\end{array}$ \\
\hline Bias & 9 & $\begin{array}{l}\text { Describe any efforts to address potential sources of bias } \\
\text { The presence of a possible selection bias is reported in the Limitations }\end{array}$ \\
\hline Study size & 10 & $\begin{array}{l}\text { Explain how the study size was arrived at } \\
\text { Sample determination is reported in the "Study design and treatment" paragraph of the Methods section. } \\
\text { Sample size calculation was based on the difference in means for the primary outcome (change in IPSS } \\
\text { total score) among } 3 \text { independent groups. For a two-sided paired Student's t-test, with } \alpha \text { and power } \\
\text { equal to } 5 \% \text { and } 90 \% \text {, the enrollment of } 30 \text { patients per group was required to detect a minimum clini- } \\
\text { cally significant difference between the changes of IPSS score measured at baseline and at follow-up }\end{array}$ \\
\hline Quantitative variables & 11 & $\begin{array}{l}\text { Explain how quantitative variables were handled in the analyses. If applicable, describe which groupings } \\
\text { were chosen and why } \\
\text { Use of variables is discussed in the "Statistical analysis" subsection }\end{array}$ \\
\hline
\end{tabular}


Table 1 (continued)

Item no Recommendation

Statistical methods

Results

Participants

Descriptive data

Outcome data

Main results

Other analyses

Discussion

Key results

Limitations

Interpretation

Generalisability

Other information

Funding (a) Describe all statistical methods, including those used to control for confounding

(b) Describe any methods used to examine subgroups and interactions

(c) Explain how missing data were addressed

(d) If applicable, explain how loss to follow-up was addressed

(e) Describe any sensitivity analyses

Statistical methods are discussed in the "Statistical analysis" subsection a) Report numbers of individuals at each stage of study—eg numbers potentially eligible, examined for eligibility, confirmed eligible, included in the study, completing follow-up, and analyzed

(b) Give reasons for non-participation at each stage

(c) Consider use of a flow diagram

Numbers examined for eligibility, confirmed eligible, included in the study, completing follow-up, and analyzed are reported in the "Study design and treatment" subsection

(a) Give characteristics of study participants (eg demographic, clinical, social) and information on exposures and potential confounders

(b) Indicate number of participants with missing data for each variable of interest

(c) Summarize follow-up time (eg, average and total amount)

Characteristics of study participants are reported in the "Characteristics of subjects undergoing bariatric surgery" subsection and in Table 2. Follow-up time is reported in the "Study design and treatment" subsection. There were no missing data for the outcomes considered in this manuscript

Report numbers of outcome events or summary measures over time Measures are reported throughout the Results Section

16 (a) Give unadjusted estimates and, if applicable, confounder-adjusted estimates and their precision (eg, 95\% confidence interval). Make clear which confounders were adjusted for and why they were included

(b) Report category boundaries when continuous variables were categorized

N/A

(c) If relevant, consider translating estimates of relative risk into absolute risk for a meaningful time period N/A

N/A

18 Summarize key results with reference to study objectives

Results are summarized in the Discussion section, page 17

19 Discuss limitations of the study, taking into account sources of potential bias or imprecision. Discuss both direction and magnitude of any potential bias

Limitations are discussed in the second-to-last paragraphs of the Discussion section (pages 21-22)

Give a cautious overall interpretation of results considering objectives, limitations, multiplicity of analyses, results from similar studies, and other relevant evidence

See final paragraph of the Discussion section

21 Discuss the generalisability (external validity) of the study results

See limitations in the second-to-last paragraphs of the Discussion section (pages 21-22)

22 Give the source of funding and the role of the funders for the present study and, if applicable, for the original study on which the present article is based

Funding is reported in the Title Page. The original study on which the present article is based is registered and described in the U.S. National Library of Medicine Registry (ClinicalTrials.gov Identifier: NCT02248467)

*Give information separately for exposed and unexposed groups

and registered on the U.S. National Library of Medicine Registry (ClinicalTrials.gov Identifier: NCT02248467). Informed consent was obtained before initiation of any clinical procedure.
The primary outcome of the clinical study was to evaluate the effect of TTh on Lower Urinary Tract Symptoms (LUTS) in severely obese men with moderate to severe urinary symptoms, as evaluated by the International Prostate 
Symptom Score (IPSS) questionnaire [34]. Sample size calculation was based on the difference in means for the primary outcome among 3 independent groups and required the enrollment of 30 patients per group. The results of the primary outcome are not reported in this manuscript and will be described in future publications. The analysis of the effect of TTh on preadipocytes isolated from visceral adipose tissue and on histomorphometric and molecular parameters of liver tissue had been planned as secondary outcomes and are reported in this paper.

\section{Patient recruitment}

Patients with a recommendation for surgical treatment of obesity were initially screened at the General, Bariatric and Metabolic Surgery Unit, Santa Maria Nuova Hospital, Florence, Italy. Among the 125 patients screened, 103 were confirmed eligible and included; reasons for screening failure are reported in the study flow-chart (Fig. 1).

Eligible subjects were then informed about the study and those agreeing to participate were sent to the Sexual Medicine and Andrology Unit of the Careggi University Hospital (University of Florence) where the procedures pertaining to the baseline visit (V0) were performed from May 2013 to December 2016.

\section{Inclusion and exclusion criteria}

All the following were considered as inclusion criteria for the present study: male subjects aged between 25 and 65 years; candidate for a bariatric surgery [body mass index $(\mathrm{BMI}) \geq 40 \mathrm{~kg} / \mathrm{m}^{2}$, or BMI is $>35 \mathrm{~kg} / \mathrm{m}^{2}$ with obesity-related comorbidities, such as type 2 diabetes mellitus, hypertension and cardiovascular disease]. LUTS were defined by IPSS total score $\geq 8$. All the following were considered as exclusion criteria: bladder failure or neurogenic bladder; post-void residual urine volume $>250 \mathrm{~mL}$; multiple sclerosis, Parkinson's disease, spinal cord injury; urethral stenosis, diverticula; history of prostatectomy, bladder neck surgery, transurethral resection of the prostate (TURP); severe systemic disease, including previous or active cancer; alcohol or drug abuse; uncontrolled psychiatric diseases.

\section{Interventions}

According to the recommendations of the International Society of Andrology (ISA), the ISSAM and the European Association of Urology (EAU) [35], hypogonadism was defined as levels of total testosterone $(T)<12 \mathrm{nmol} / \mathrm{L}$ and/ or free $T<225 \mathrm{pmol} / \mathrm{L}$, calculated according to Vermeulen's
Fig. 1 Flow-chart for the observational study. $T$ testosterone, $T T h$ testosterone therapy, $F U$ follow-up

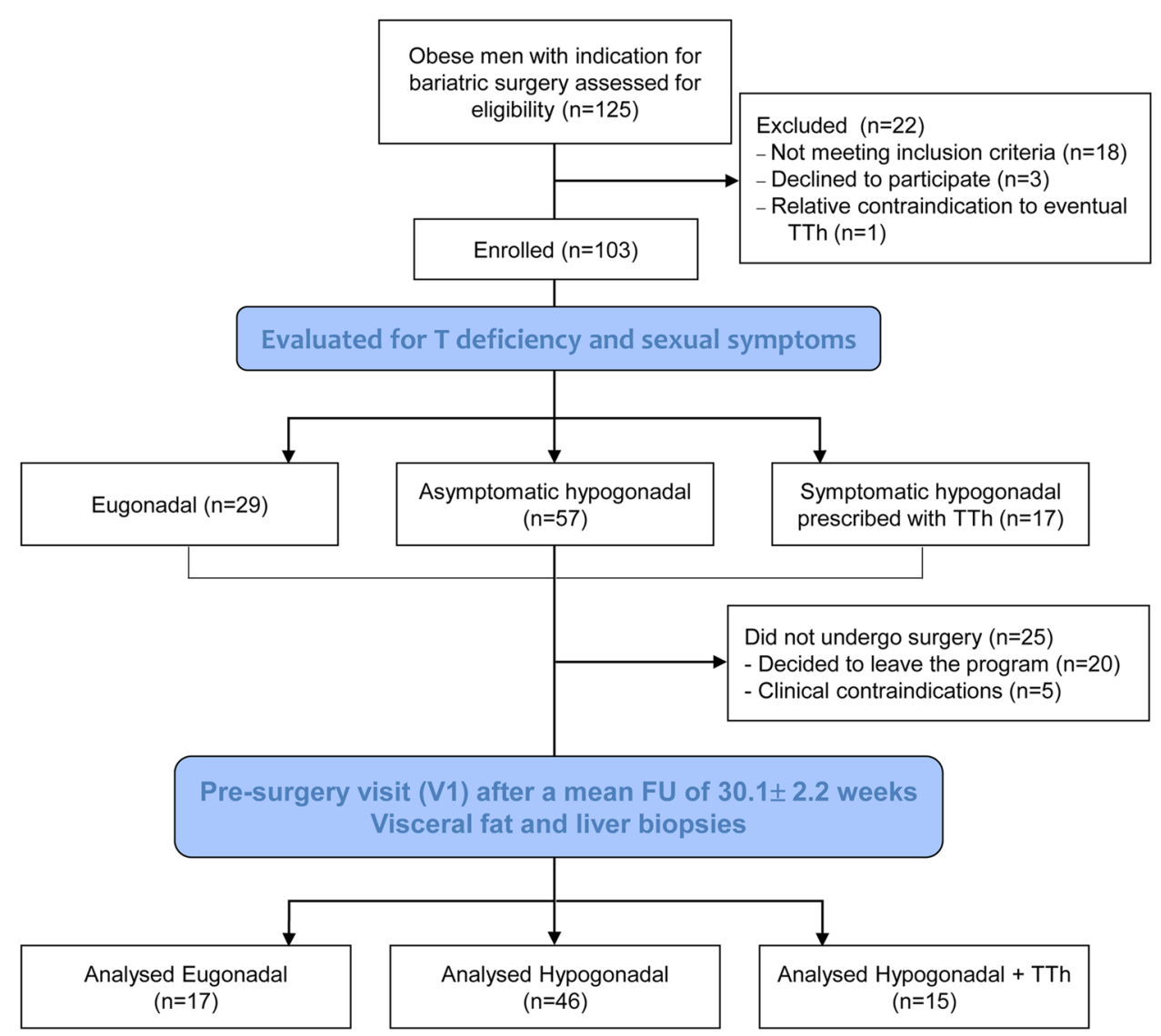


formula [36]. Based on the same recommendations, in line with the observational nature of the study, the decision of starting TTh was made in men with low $T$ (total or free) and symptoms consistent with $T$ deficiency, in particular sexual symptoms, which are considered to be the most specific to the condition [37]. Therefore, patients were defined as symptomatic when they reported the presence of all the symptoms explored by the 5 questions composing the sexual sub-score of the Aging Males' Symptoms (AMS) scale [38] (see 2.6, "Clinical parameters"- -feeling to have passed one's peak, decrease in beard growth, impaired sexual potency, less morning erections, disturbed libido), thus obtaining a score of at least 10 in the sub-score.

Hence, enrolled patients were divided into three groups: eugonadal (EUG; $n=29$ ), untreated hypogonadal (HYPO; $n=57$ ) and symptomatic hypogonadal subjects (HYPO + TTh; $n=17)$. Symptomatic hypogonadal obese men received testosterone undecanoate ( $1000 \mathrm{mg}$ i.m.) every 12 weeks after loading (second dose after 6 weeks). The treatment was prescribed to symptomatic men as soon as the results for total and calculated free $\mathrm{T}$ became available, usually within one week from V0. The choice of using this preparation has been made because injectable preparations, in contrast with transdermal ones, are characterized by a lower variability in the absorption [39]. The variability in transdermal absorption is mainly determined by the subcutaneous adipose tissue representation [39] and, therefore, we considered transdermal $T$ preparation as unsuitable for severely obese men. Among the injectable preparations, long acting $T$ undecanoate is the least likely to produce side effects, due to the stable plasmatic $T$ concentrations achieved after its injection and maintained for the 12-week period [39].

\section{Follow-up}

No drop-outs were registered during the study. However, 25 patients did not undergo bariatric surgery because they decided to leave the program or because no-TTh related clinical contraindications arose (Fig. 1). All the patients that actually underwent surgery $(n=78)$ completed the follow-up visit (V1) immediately before, providing data for the analyses reported in this article. Of these, $n=17$ were eugonadal (EUG), $n=46$ were untreated hypogonadal (HYPO) and $n=15$ were treated symptomatic hypogonadal (HYPO + TTh; $n=15)$. The mean length of follow up was $30.1 \pm 2.2$ weeks.

During bariatric surgery, samples of liver and adipose tissue were taken, after a specific informed consent, for further analyses. Preadipocyte cell cultures (hPADs) were isolated from the visceral tissue specimens, whereas liver biopsies underwent histological examination for NAFLD scoring.

\section{Clinical parameters}

At baseline (V0) and follow-up visit (V1), a physical examination was performed with measurements of body weight, height, BMI and waist circumference. BPH/LUTS symptoms were assessed by IPSS [34]. All patients were also asked to complete the Heinemann's Aging Males' Symptoms (AMS) scale [38] in its validated Italian version [40]. The AMS is a self-reported scale developed to quantify health-related quality of life and symptoms of aging men and is useful in both the diagnosis of hypogonadism and the monitoring of patients using testosterone therapy [41]. The AMS scale encompasses 17 questions with three sub-scales, including mind-, body- and sexual-related symptoms. Answers are codified with a 1-5 range (no symptom to extremely severe), and the total sum of all sub-scales provides a total score. A subset of patients underwent transrectal color-Doppler ultrasonography (CDUS) for the study of the prostate, according to previously published procedures [42], to assess LUTSrelated secondary outcomes not reported in this paper.

\section{Biochemical, metabolic and histological analyses}

Blood samples for biochemical and metabolic parameters were obtained from patients at baseline (V0) and at followup visit (V1). In particular, blood samples were drawn in the morning after an overnight fast to determine total testosterone (chemiluminescence immunoassay; Advia Centaur, Siemens, Berlin, Germany), sex hormone binding globulin (SHBG; electro-chemiluminescence immunoassay; COBAS 600, Roche Diagnostics, Basel, Switzerland); 17 $\beta$-estradiol (luminescent oxygen channeling immunoassay; Vista, Siemens, Berlin, Germany); blood glucose (glucose hexokinase method; Dimension Vista 1500, Medical Solutions Siemens Healthcare, Malvern, PA); total cholesterol, high-density lipoprotein cholesterol (HDL), and triglycerides (automated enzymatic colorimetric method; Dimension Vista 1500, Medical Solutions Siemens Healthcare); insulin (electrochemiluminescence immunoassay; Roche Diagnostics, Mannheim, Germany); aspartate aminotransferase (AST), alanine aminotransferase (ALT) and gammaglutamyl-transferase $(\gamma \mathrm{GT})$ (LOCI $®$ luminescent oxygen channeling immunoassay, advanced homogeneous chemiluminescence; Dimension Vista 1500, Medical Solutions Siemens Healthcare); low-density lipoprotein cholesterol was estimated indirectly using the Friedewald equation [low-density lipoprotein cholesterol $=$ total cholesterol / (high-density lipoprotein cholesterol + triglycerides/5)], where all parameters are expressed in milligrams per deciliter.

Total and/or free testosterone measured at baseline (V0) were used to categorize patients into the 3 analytical groups (see above). 
The fatty liver index (FLI), and index of hepatic steatosis, was calculated as: FLI $=[\mathrm{e} 0.953 * \operatorname{loge}$ (triglycerides $)+0.139 * \mathrm{BMI}+0.718 * \operatorname{loge}(\mathrm{GGT})+0.053 *$ waist circumference-15.745]/[1+e $0.953 * \operatorname{loge}$ (triglycerides $)+0.139 *$ BMI $+0.718 * \log$ e $($ GGT $)+0.053 *$ waist circumference-15.745] * 100, as in Bedogni et al. [43]. Calculated free testosterone was derived according to the formula of Vermeulen and collaborators (available at https ://www.issam.ch/freetesto.htm) [36]. Triglyceride content from liver biopsies was evaluated using the Triglyceride Quantification Colorimetric/Fluorometric Kit (BioVision, Milpitas, CA), following the manufacturer's instructions.

Liver biopsies were processed routinely for paraffin embedding, and 3 micron-thick sections were prepared for histological analysis, as previously described [29]. For each sample, three to five sections were cut along the length. Hematoxylin and eosin-stained sections were used for direct microscopic examination, using the Nikon Microphot-FXA microscope (Nikon, Tokyo, Japan).

\section{Isolation, characterization and differentiation of human visceral fat preadipocytes}

Human visceral fat preadipocytes (hPADs) isolation was performed, as previously described [8]. After dissection under sterile conditions, visceral adipose tissue (VAT) samples were immediately placed in serum-free (SF) DMEM/ F12, supplemented with $200 \mu \mathrm{g} / \mathrm{mL}$ streptomycin and 200 $\mathrm{U} / \mathrm{mL}$ penicillin, and then digested with type 2 collagenase $\left(1 \mathrm{mg} / \mathrm{mL}\right.$ in PBS) for $1 \mathrm{~h}$ at $37^{\circ} \mathrm{C}$. After filtration and centrifugation the cells pellet was plated onto $100-\mathrm{mm}$ cell culture dishes and cultured, at $37{ }^{\circ} \mathrm{C}$ in humidified atmosphere of $95 \%$ air-5\% $\mathrm{CO}_{2}$, in complete culture medium (DMEM containing $10 \% \mathrm{FBS}, 100 \mu \mathrm{g} / \mathrm{mL}$ streptomycin, $100 \mathrm{U} / \mathrm{mL}$ penicillin, $2 \mathrm{mM}$ l-glutamine, and $1 \mu \mathrm{g} / \mathrm{mL}$ amphotericin-B).

Conjugated monoclonal antibodies CD34-FITC, CD45FITC, CD31-PE, CD14-PE, CD90-FITC, CD106-PE and CD105-PE were used to characterize hPADs at P1 by flow cytometry. hPADs isolated from the different groups showed a similar immunophenotypic profile, characterized by mesenchymal stem cell markers (CD90, CD105, and CD106). Moreover, all hPADs were negative for endothelial (CD31), hematopoietic (CD34 and CD45), and monocytic (CD14) markers.

The hPADs differentiation, 2 days after confluence (time 0 ), was induced by exposing cells to a differentiation mixture (DIM) containing $5 \mathrm{mg} / \mathrm{mL}$ insulin, $1 \mathrm{mM}$ dexamethasone, and $0.5 \mathrm{mM} 3$-isobutyl-1-methylxanthine (IBMX) in 5\% stripped FBS-supplemented DMEM for 8 days. The culture medium was replaced every $48 \mathrm{~h}$, and then the cells were shifted to a medium containing $5 \mathrm{mg} / \mathrm{mL}$ insulin for $48 \mathrm{~h}$.

\section{RNA extraction and quantitative RT-PCR analysis}

Isolation of total RNA from tissues and hPADs was performed using TRIzol reagent (Life Technologies, Paisley, UK) and/or Qiagen RNeasy Mini Kit (Qiagen, Hilden, Germany), in accordance with the manufacturer's instruction. cDNA synthesis and real-time RT-PCR experiments were performed using reagents and instrumentation from Bio-Rad Laboratories (Hercules, CA), as previously described [44]. Specific PCR oligonucleotides were based on sequences obtained from Ensemble Genome (https://www.ensem bl.org) and NCBI GenBank (https://www.ncbi.nlm.nih.gov). The 18S ribosomal RNA subunit was used as the reference gene for the relative quantization of the target genes based on the comparative threshold cycle $(\mathrm{Ct}) 2^{-\Delta \Delta \mathrm{Ct}}$ method [45].

\section{Glucose uptake}

Glucose uptake in DIM-hPADs was performed as follows: hPADs were shifted in SF medium for $24 \mathrm{~h}$, followed by increasing concentrations of insulin $(1,5,10$, and $50 \mathrm{nM}$ for $30 \mathrm{~min}$ ) diluted in glucose-free Krebs phosphate buffer $\left(2.5 \mathrm{mmol} \mathrm{Ca}{ }^{2+}, 1 \mathrm{mg} / \mathrm{mL}\right.$ BSA), to evaluate insulin-dependent stimulation. After insulin incubation, the cells were further incubated with ${ }^{3} \mathrm{H}-2$-deoxy-D-glucose $[16 \mathrm{mM}(1 \mathrm{mCi} /$ $\mathrm{mL})]$ for $10 \mathrm{~min}$. Cells were then washed with PBS, lysed with $\mathrm{NaOH} 0.5 \mathrm{M}$, and incorporated radioactivity was measured by scintillation spectrometry using a $\beta$-counter.

\section{Fluorescence microscopy}

To evaluate the mitochondrial network and dynamics DIMinduced hPADs isolated from each experimental group, were cultured on $35 \mathrm{~mm}$ u-Dish (Ibidi GmbH, Munich, Germany) for 10 days and then stained with $200 \mathrm{nM}$ MitoTracker Green $^{\mathrm{FM}}$ (Invitrogen Life Technologies, Carlsbad, CA), as previously described [8]. Cells were imaged, with time lapses recorded for 3 min with time intervals of $10 \mathrm{~s}$, using an inverted Leica DMI6000 microscope (Leica, Wetzlar, Germany) equipped with a stage incubator (Pecon, Erbach, Germany) with controlled temperature, humidity and $\mathrm{CO}_{2}$.

Superoxide radical production in hPADs was monitored by dihydroethidium (DHE; Invitrogen) fluorescence and quantified by measuring the change in fluorescence intensity in the nuclei of rPAD cells during imaging, as previously described [8].

Images were captured through a $63 \times 1.2 \mathrm{NA}$ water immersion objective, with a DFC350FX camera and Leica filter set L5 (for MitoTracker Green), and N2.1 and N3 (for DHE). All image analyses were performed using Fiji ImageJ software [46]. 


\section{Oxygen consumption analysis}

Quantification of oxygen consumption by hPADs isolated from each experimental group was conducted by means of the Oxygraph system (Hansatech Instruments, Pentney, UK), as previously described [47]. Briefly, cells $\left(7.5 \times 10^{4}\right)$ were loaded in the chamber, which contained $300 \mu \mathrm{L}$ of DMEM with glutamine $2 \mathrm{mM}$ and sodium succinate $20 \mathrm{mM}$. Oxygen consumption was monitored for $5 \mathrm{~min}$ at $37^{\circ} \mathrm{C}$.

\section{Statistical analysis}

Results are expressed as mean \pm SEM, when normally distributed, and median [interquartile range] and SEM when nonnormally distributed.

Differences between EUG, HYPO and HYPO + TTh in molecular and morphological parameters were assessed by Kruskal-Wallis test adjusted for multiple comparisons followed by Mann-Whitney test where appropriate to evaluate differences between the groups, with $p<0.05$ considered as significant. Correlations were assessed using Spearman's method, and the statistical analysis was performed with the Statistical Package for the Social Sciences for Windows (SPSS v.26.0; SPSS Inc., Chicago, IL). Half-maximal response effective concentration $\left(\mathrm{EC}_{50}\right)$ values and maximal effect $\left(E_{\max }\right)$ values were calculated using the computer program ALLFIT [48].

Changes over time between and within HYPO and HYPO + TTh groups were assessed by the multilevel mixedeffects linear regression, which takes into account the effect of time and treatment and their interaction. These data were adjusted for the baseline value of the outcome variable and for age and baseline BMI. These analyses were conducted using Stata MP 13.1 for Windows (Stata Corp, College Station, TX).

For the aforementioned analyses, which evaluated changes over time in clinical, biochemical and instrumental parameters, HYPO was considered as the comparator group. For the analyses performed on samples of adipose or liver tissue, which do not have a baseline and follow-up evaluation, EUG was considered as the comparator.

\section{Results}

\section{Characteristics of subjects undergoing bariatric surgery at baseline and at surgery}

Baseline features of the three study arms are reported in Table 2. No baseline differences between the three groups were observed, with the exception of total (TT), SHBG and calculated free testosterone (cFT) levels. As expected, TT and cFT were significantly reduced $(p<0.0001)$ in the two hypogonadal groups (untreated and testosterone-treated), as compared to eugonadal subjects (EUG:
$\mathrm{TT}=15.7 \pm 0.9 \mathrm{nmol} / \mathrm{L}, \mathrm{cFT}=311.2 \pm 14.1 \mathrm{pmol} / \mathrm{L}$; HYPO: $\mathrm{TT}=7.6 \pm 0.4 \mathrm{nmol} / \mathrm{L}, \mathrm{cFT}=157.1 \pm 6.4 \mathrm{pmol} / \mathrm{L}$; HYPO + TTh: T T $=7.4 \pm 0.5 \mathrm{nmol} / \mathrm{L}$, $\mathrm{cFT}=153.0 \pm 9.4 \mathrm{pmol} / \mathrm{L}$ ). Furthermore, consistent with the rationale for treatment, AMS sexual symptoms score at baseline was significantly higher in HYPO + TTh [12.0 (11.0-15.0)] than in EUG [6.5 (5.0-13.2)] and HYPO [7.0 (5.0-10.5)] subjects (both differences $p<0.0001$ ).

Mean duration of follow-up $(33.14 \pm 6.78,30.28 \pm 2.84$ and $27.63 \pm 3.64$ weeks in EUG, HYPO and HYPO + TTh, respectively) was not significantly different among the three groups $(p=0.863)$. Similarly, at V1, no differences were highlighted in the percentage of patients using glucose-lowering [23.5 $(n=4), 28.3(n=13)$ and $26.7 \%(n=4)$, in EUG, HYPO and HYPO + TTh, respectively; $p=0.913]$ or lipid-lowering drugs [5.9 $(n=1)$, $21.7(n=10)$ and $20.0 \%(n=3)$ in EUG, HYPO and HYPO + TTh, respectively; $p=0.324]$, and in the percentage of subjects following a pre-surgery diet plan [5.9 $(n=1), 13.0(n=6)$ and 6.7\% $(n=1)$, in EUG, HYPO and HYPO + TTh, respectively; $p=0.621]$ among the three groups. Of note, no specific medications for obesity (i.e. naltrexone-bupropion or liraglutide) were prescribed between baseline and V1.

\section{Biochemical characteristics of hypogonadal men and their change over time according to TTh}

Considering the longitudinal data, significant changes in insulin $(p<0.0001)$, triglycerides $(p=0.010)$, AST $(p=0.002)$ and ALT $(p=0.001)$ serum levels were observed between baseline and V1 in the untreated-hypogonadal patients group, but not in the TTh-treated group (Table 3). TTh-hypogonadal patients showed a significant reduction of total cholesterol and fatty liver index at the V1 pre-surgery visit, as compared to baseline $(p=0.022$ and $p=0.001$, respectively), whereas in the untreated group we observed no significant changes (Table 3 ). Figure 2 shows total (TT) and circulating free $\mathrm{T}$ (cFT) levels in these two study arms. As expected, both TT and cFT significantly increased over time in the TTh arm, but no change occurred in the untreated-hypogonadal group (Fig. 2 panels a, $\mathrm{b} ; p<0.0001$ for the interaction time $\times$ treatment for both TT and cFT). Accordingly, the Aging Males' Symptom (AMS) scale total score significantly improved in the T-treated hypogonadal patients ( $p<0.01 \mathrm{vs.} \mathrm{baseline),} \mathrm{but}$ not in the untreated-hypogonadal group (Fig. 2 panel c; $p=0.039$ for the interaction time $\times$ treatment). The differences at V1 between untreated and testosterone-treated hypogonadal patients were significant ( $p<0.0001$ for both TT and cFT, and $p<0.05$ for AMS) (Fig. 2 panels a-c). 
Table 2 Baseline characteristics of enrolled patients and differences among the three groups

\begin{tabular}{|c|c|c|c|}
\hline & Eugonadal $(n=17)$ & Hypogonadal $(n=46)$ & Hypogonadal + TTh $(n=15)$ \\
\hline Age (years) & $44.5 \pm 3.1$ & $44.7 \pm 1.4$ & $50.1 \pm 2.8$ \\
\hline BMI $\left(\mathrm{kg} / \mathrm{m}^{2}\right)$ & $42.4 \pm 1.8$ & $47.2 \pm 1.3$ & $42.5 \pm 1.2$ \\
\hline $\mathrm{WC}(\mathrm{cm})$ & $133.7 \pm 4.0$ & $146.1 \pm 2.4$ & $131.7 \pm 2.8$ \\
\hline Systolic BP (mmHg) & $126.1 \pm 3.5$ & $133.5 \pm 2.7$ & $131.7 \pm 2.8$ \\
\hline Diastolic BP (mmHg) & $77.3 \pm 2.2$ & $83.6 \pm 1.7$ & $83.0 \pm 2.3$ \\
\hline Use of on demand PDE5i \% $(n)$ & $(0)$ & $(0)$ & $(2)$ \\
\hline Use of glucose-lowering drugs \% (n) & $23.5(4)$ & $26.1(12)$ & $20.0(3)$ \\
\hline Metformin \% (n) & (4) & $(12)$ & (3) \\
\hline Repaglinide \% (n) & $(0)$ & (2) & (1) \\
\hline GLP-1 analogs \% ( $n)$ & (1) & $(0)$ & (2) \\
\hline DPPIV inhibitors \% $(n)$ & $(0)$ & $(2)$ & (1) \\
\hline Insulin $\%(n)$ & $(0)$ & (2) & $(0)$ \\
\hline Use of lipid-lowering drugs (\%) & $5.9(1)$ & $13.0(6)$ & $20.0(3)$ \\
\hline Statin $(\%)$ & (1) & (4) & (3) \\
\hline Fibrates (\%) & $(0)$ & (2) & $(0)$ \\
\hline Omega-3 fatty acids (\%) & $(0)$ & (1) & $(0)$ \\
\hline Ezetimibe (\%) & $(0)$ & (1) & $(0)$ \\
\hline Total testosterone $(\mathrm{nmol} / \mathrm{l})$ & $15.7 \pm 0.9$ & $7.6 \pm 0.4^{*}$ & $7.4 \pm 0.5^{*}$ \\
\hline SHBG (nmol/l) & $38.2[34.6-46.9]$ & $25.0[14.6-34.9]^{\circ}$ & $32.3[18.6-34.5]^{\circ}$ \\
\hline $\mathrm{cfT}(\mathrm{pmol} / \mathrm{l})$ & $311.2 \pm 14.1$ & $157.1 \pm 6.4^{*}$ & $153.0 \pm 9.4^{*}$ \\
\hline LH (U/l) & $5.6[3.4-6.7]$ & $3.8[2.7-5.4]$ & $3.2[1.8-5.1]$ \\
\hline $17 \beta$ estradiol $(\mathrm{pmol} / \mathrm{l})$ & $153.5[104.2-180.0]$ & $130.0[95.0-150.0]$ & $101.0[85.0-140.0]$ \\
\hline Hematocrit (\%) & $44.5 \pm 1.3$ & $45.1 \pm 0.5$ & $44.5 \pm 1.2$ \\
\hline PSA (ng/dl) & $0.5[0.3-0.7]$ & $0.5[0.3-0.9]$ & $0.5[0.4-1.3]$ \\
\hline Glycaemia (g/l) & $1.1 \pm 0.1$ & $1.2 \pm 0.1$ & $1.2 \pm 0.1$ \\
\hline $\mathrm{HbA1c}(\mathrm{mmol} / \mathrm{mol})$ & $40.2 \pm 2.2$ & $45.4 \pm 2.6$ & $46.3 \pm 3.7$ \\
\hline Triglycerides (mg/dl) & 97.0 [74.0-188.0] & $145.0[110.0-205.5]$ & $152.0[105.0-236.0]$ \\
\hline Total cholesterol (mg/dl) & $187.6 \pm 9.8$ & $208.3 \pm 8.3$ & $199.4 \pm 10.7$ \\
\hline HDL cholesterol (mg/dl) & $44.1 \pm 2.4$ & $42.6 \pm 1.7$ & $39.0 \pm 1.5$ \\
\hline LDL cholesterol (mg/dl) & $115.0 \pm 5.7$ & $133.5 \pm 7.1$ & $118.9 \pm 9.6$ \\
\hline T2DM \% (n) & (4) & (9) & (3) \\
\hline Hypertension \% ( $n)$ & (7) & (20) & (9) \\
\hline Cardiovascular diseases $\%(n)$ & (4) & (4) & $(2)$ \\
\hline MetS \% $(n)$ & $61.5(8)$ & $87.5(35)$ & $80(12)$ \\
\hline AMS total score & $30.5[26.0-34.5]$ & $32.5[25.5-39.5]$ & $32.0[26.0-40.0]$ \\
\hline AMS sexual symptoms score & $6.5[5.0-13.2]$ & $7.0[5.0-10.5]$ & $12.0[11.0-15.0]^{*}$ \\
\hline IPSS total score & $10[8-25]$ & $8[8-24]$ & $10[8-16]$ \\
\hline
\end{tabular}

Data are expressed as mean \pm SEM when normally distributed and as percentages when categorical. Bold value indicates statistical significance difference. ${ }^{*} p<0.0001,{ }^{\circ} p<0.05$ vs. Eugonadal

TTh testosterone therapy, $B M I$ body mass index, $W C$ waist circumference, $B P$ blood pressure, $P D E 5 i$ phosphodiesterase type 5 inhibitors, $G L P$ glucagon-like peptide-1, DPPIV dipeptidyl peptidase 4, SHBG sex hormone binding globulin, $c F T$ calculated free testosterone, $L H$ luteinizing hormone, $P S A$ prostate specific antigen, $H b A l c$ glycated hemoglobin, $H D L$ high-density lipoprotein, $L D L$ low-density lipoprotein, $T 2 D M$ type 2 Diabetes Mellitus, MetS Metabolic Syndrome, AMS Aging Males' Symptoms scale, IPSS International Prostatic Symptoms Score

\section{Correlations between liver biopsies scores, TTh and CFT levels and liver triglycerides levels at time of surgery}

Figure 3 reports liver NAFLD activity score (NAS) and steatosis score according to the three experimental groups (eugonadal, untreated hypogonadal and T-treated hypogonadal). NAS score was significantly higher in the hypogonadal than in the eugonadal group $(p<0.05)$, whereas it was significantly lower in the treated hypogonadal vs. hypogonadal group $(p<0.05)$, showing no significant difference from the eugonadal group (Fig. 3, panel a). Worth noting, 
Table 3 Characteristics of hypogonadal untreated (HYPO) and testosterone-treated (HYPO + TTh) patients at baseline and before surgery (V1)

\begin{tabular}{|c|c|c|c|c|}
\hline Variable & Treatment & Baseline & V1 & $\begin{array}{l}\text { V1 vs. baseline } \\
\text { within group } \\
(p)\end{array}$ \\
\hline BMI $\left(\mathrm{kg} / \mathrm{m}^{2}\right)$ & $\begin{array}{l}\text { HYPO } \\
\text { HYPO }+ \text { TTh } \\
\text { Interaction time } \times \text { treatment } p=0.665\end{array}$ & $\begin{array}{l}46.6[43.7-49.3] \\
46.1[41.6-50.7]\end{array}$ & $\begin{array}{l}47.6[44.6-50.6] \\
45.5[41.0-50.0]\end{array}$ & $\begin{array}{l}0.619 \\
0.848\end{array}$ \\
\hline Fasting glucose (mg/dL) & $\begin{array}{l}\text { HYPO } \\
\text { HYPO }+ \text { TTh } \\
\text { Interaction time } \times \text { treatment } p=0.275\end{array}$ & $\begin{array}{l}119.8[106.6-133.0] \\
123.3[104.1-142.3]\end{array}$ & $\begin{array}{l}138.6[124.9-152.4] \\
122.8[100.2-145.4]\end{array}$ & $\begin{array}{l}\mathbf{0 . 0 5 0} \\
0.979\end{array}$ \\
\hline Insulin (mU/L) & $\begin{array}{l}\text { HYPO } \\
\text { HYPO + TTh } \\
\text { Interaction time } \times \text { treatment } p=0.494\end{array}$ & $\begin{array}{l}39.2[31.1-47.2] \\
36.0[24.1-48.0]\end{array}$ & $\begin{array}{l}16.6[8.2-25.1] \\
21.3[6.0-36.6]\end{array}$ & $\begin{array}{l}<0.0001 \\
0.130\end{array}$ \\
\hline Total cholesterol (mg/dL) & $\begin{array}{l}\text { HYPO } \\
\text { HYPO }+ \text { TTh } \\
\text { Interaction time } \times \text { treatment } p=0.059\end{array}$ & $\begin{array}{l}201.8[191.7-211.8] \\
204.5[189.4-219.6]\end{array}$ & $\begin{array}{l}201.1[190.7-211.5] \\
177.8[159.9-195.6] *\end{array}$ & $\begin{array}{l}0.927 \\
\mathbf{0 . 0 2 2}\end{array}$ \\
\hline HDL cholesterol (mg/dL) & $\begin{array}{l}\text { HYPO } \\
\text { HYPO }+ \text { TTh } \\
\text { Interaction time } \times \text { treatment } p=0.165\end{array}$ & $\begin{array}{l}41.0[38.7-43.2] \\
41.2[37.8-44.6]\end{array}$ & $\begin{array}{l}38.7[36.3-41.0] \\
34.6[30.6-38.6]\end{array}$ & $\begin{array}{l}0.154 \\
\mathbf{0 . 0 1 1}\end{array}$ \\
\hline Triglycerides (mg/dL) & $\begin{array}{l}\text { HYPO } \\
\text { HYPO }+ \text { TTh } \\
\text { Interaction time } \times \text { treatment } p=0.464\end{array}$ & $\begin{array}{l}153.5[133.9-176.0] \\
143.3[116.7-175.9]\end{array}$ & $\begin{array}{l}197.3[171.2-227.3] \\
160.9[126.1-205.4]\end{array}$ & $\begin{array}{l}\mathbf{0 . 0 1 0} \\
0.456\end{array}$ \\
\hline $\begin{array}{l}\text { Aspartate aminotransferase } \\
\text { (AST; U/L) }\end{array}$ & $\begin{array}{l}\text { HYPO } \\
\text { HYPO }+ \text { TTh } \\
\text { Interaction time } \times \text { treatment } p=0.373\end{array}$ & $\begin{array}{l}28.4[20.6-36.2] \\
31.1[19.6-42.5]\end{array}$ & $\begin{array}{l}45.3[37.4-53.2] \\
38.7[24.7-52.7]\end{array}$ & $\begin{array}{l}\mathbf{0 . 0 0 2} \\
0.386\end{array}$ \\
\hline $\begin{array}{l}\text { Alanine aminotransferase } \\
\text { (ALT; U/L) }\end{array}$ & $\begin{array}{l}\text { HYPO } \\
\text { HYPO }+ \text { TTh } \\
\text { Interaction time } \times \text { treatment } p=0.076\end{array}$ & $\begin{array}{l}45.0[35.2-54.9] \\
50.6[36.1-65.0]\end{array}$ & $\begin{array}{l}67.9[57.8-77.9] \\
50.0[32.4-67.7]\end{array}$ & $\begin{array}{l}\mathbf{0 . 0 0 1} \\
0.960\end{array}$ \\
\hline Fatty Liver Index & $\begin{array}{l}\text { HYPO } \\
\text { HYPO }+ \text { TTh } \\
\text { Interaction time } \times \text { treatment } p=0.007\end{array}$ & $\begin{array}{l}99.1[98.8-99.4] \\
99.2[98.8-99.7]\end{array}$ & $\begin{array}{l}99.1[98.8-99.3] \\
98.4[97.9-98.8] *\end{array}$ & $\begin{array}{l}0.797 \\
\mathbf{0 . 0 0 1}\end{array}$ \\
\hline
\end{tabular}

Data are expressed as mean with range in brackets. Data were adjusted for the baseline value of the outcome variable and for age and baseline BMI. Significant differences are in bold

$* \mathrm{p}<0.001$ vs Hypogonadal

similar findings were observed when liver biopsies were analyzed for the steatosis score (Fig. 3, panel b). Furthermore, considering cFT quartiles measured at V1 (pre-surgery visit), we observed significant negative age-adjusted correlations with steatosis $(r:-0.362, p<0.01)$ and inflammation scores $(r:-0.438, p<0.05)$.

Intrahepatic triglyceride (TG) levels obtained from liver biopsies collected during surgical procedure resulted in being significantly higher in the hypogonadal group, when compared to eugonadal subjects (Fig. 4 panel a; $p<0.05$ ). Interestingly, T-treated hypogonadal subjects showed significantly reduced intrahepatic TG level, with respect to untreated-hypogonadal subjects (Fig. 4 panel a; $p<0.05$ vs. hypogonadal), reaching a level that was almost identical to that observed in eugonadal patients. Considering all groups, intrahepatic TG levels correlated positively with both steatosis (Fig. 4 panel b; $p<0.001$ ) and NAS scores (Fig. 4 panel c; $p<0.001)$. Hepatic histomorphological analysis, performed using H\&E staining, demonstrated that hypogonadism was associated with a prominent lipid accumulation within the hepatocytes, compared to eugonadal patients (Fig. 4 panels d, e, respectively). In contrast, macrovesicular steatosis was dramatically reduced in testosterone-treated hypogonadal subjects (Fig. 4 panel f).

\section{Treatment with testosterone enhances the expression of genes involved in lipid metabolism and insulin signaling in liver tissue}

In the liver, testosterone treatment resulted in an increased mRNA expression of several genes involved in hepatic lipid and glucose/glycogen metabolism (Fig. 5 panel a). A significant increase was observed for mRNA expression of key enzymes related to the balance between hepatic lipid accumulation and $\beta$-oxidation, such as FAS, or related to ketogenesis, including HMGCS. The lipotoxicity protective factor, SCD1, 
A

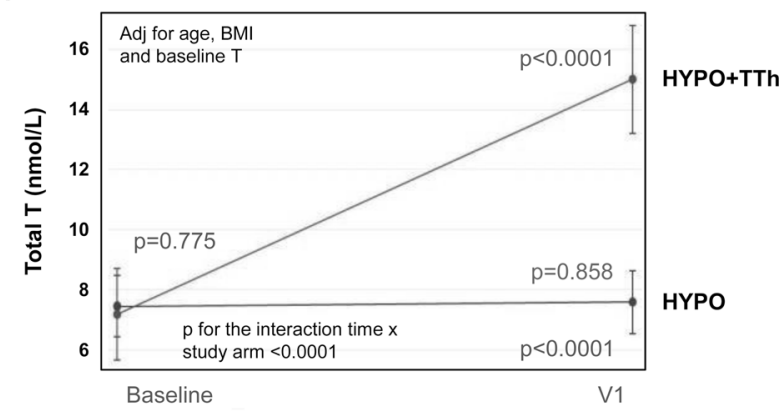

B

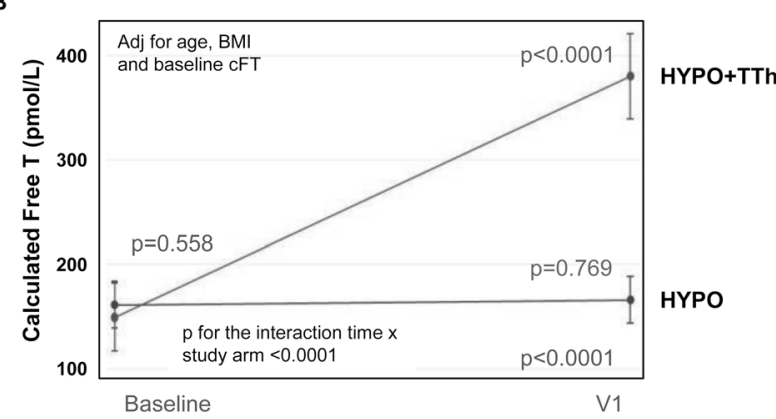

C

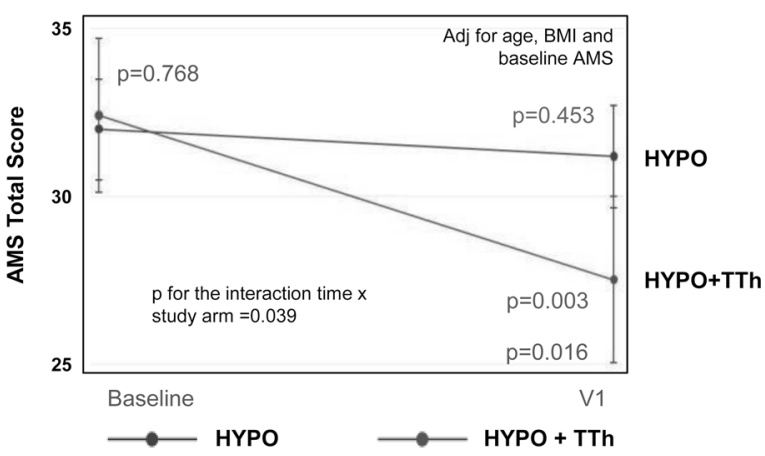

Fig. 2 Variation of biochemical and clinical parameters relative to hypoandrogenism in hypogonadal (HYPO) vs. hypogonadal subjects treated with testosterone (HYPO+TTh), V1 (surgery) vs. baseline. Data were adjusted for the baseline value of the outcome variable and for age and baseline BMI. AMS Aging Males' Symptoms scale, BMI body mass index, $c F T$ calculated free testosterone, $T$ testosterone, $T T h$ testosterone therapy

and other enzymes related to lipid metabolism, such as ACLY and HMGCR, were upregulated in TTh-hypogonadal subjects (Fig. 5 panel a). Interestingly, mRNA expression of most of these enzymes correlated positively with cFT at pre-surgery V1 (Fig. 5 panels b-e). In the liver, a clear increase trend in the mRNA expression of key enzymes involved in glycogen synthesis was induced by TTh, in particular with significant upregulation of GYS2 mRNA (Fig. 5 panel a). Likewise, the mRNA expression of genes involved in glucose transport and insulin signaling (GLUT2, GLUT4, IRS1 and STAMP2) was also significantly increased by TTh (Fig. 5 panel a), with GLUT4 liver mRNA expression showing a trend for positive
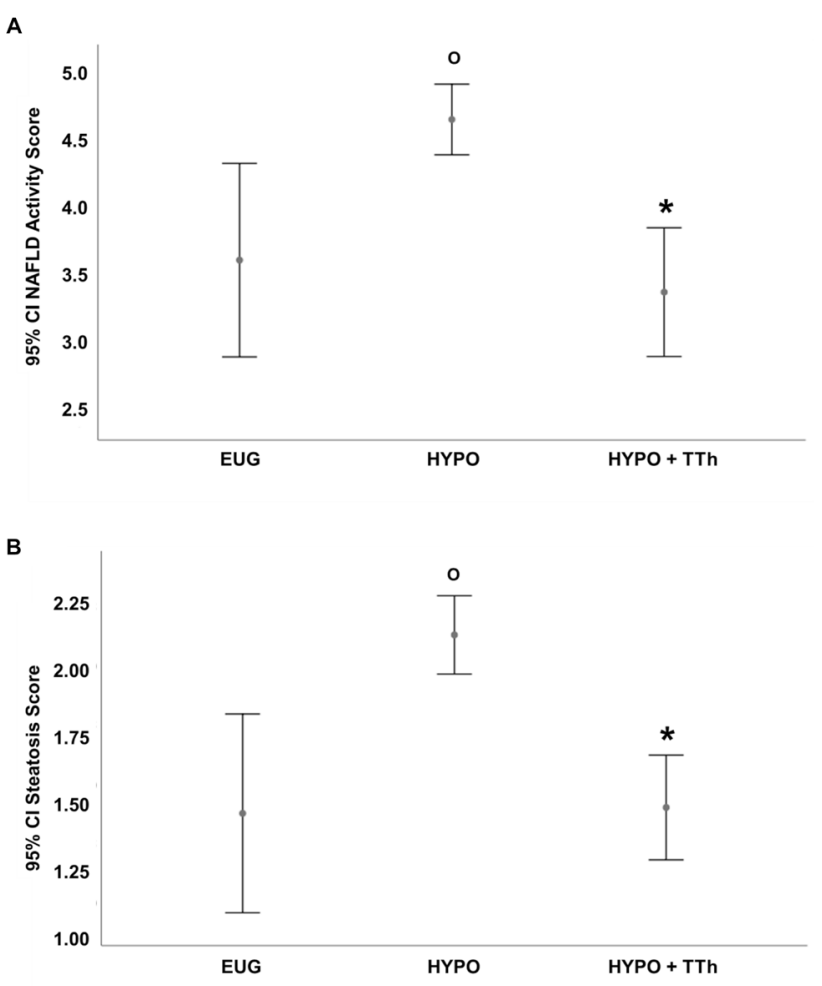

Fig. 3 Nonalcoholic Fatty Liver Disease (NAFLD) Activity Score (NAS) (a) and Steatosis Score (b) derived from liver biopsies according to the three experimental groups. ${ }^{\circ} p<0.05$ vs. Eugonadal; $* p<0.05$ vs. Hypogonadal

correlation with cFT, although without reaching statistical significance (Fig. 5 panel $\mathrm{f} ; p=0.077$ ). We also found a close positive correlation between AR and the mRNA expression of several liver genes that participate in the regulation of lipid and glucose metabolism (Table 4).

\section{Effects of testosterone treatment on the expression of genes involved in brown adipogenesis, lipid catabolism and mitochondrial bio-functionality in visceral fat tissue}

When visceral fat tissue biopsies obtained at surgery were examined, we observed that TTh was associated with a sharp increase of the mRNA expression of several genes involved in mitochondrial biogenesis (NRF1, TFAM) and function (FIS1, FOXC2, NDUFB3, NDUFB5, NDUFS1, SDHB), when compared to both untreated hypogonadal and eugonadal subjects (Fig. 6). Additionally, when compared to hypogonadal patients, TTh was also associated with an increased mRNA expression of brown adipogenesis marker PPARGC1a $(p<0.01)$. Accordingly, master regulators of white adipogenesis, namely PPAR $\gamma 2$ and DKK1, which were significantly increased in untreatedhypogonadal subjects, were normalized in T-treated 
A

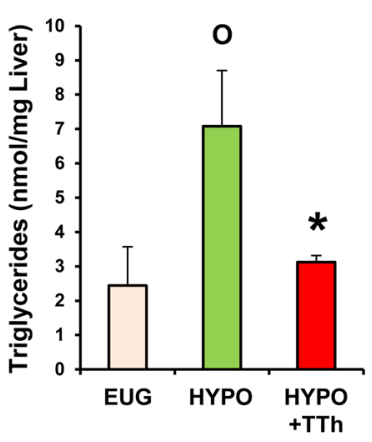

D

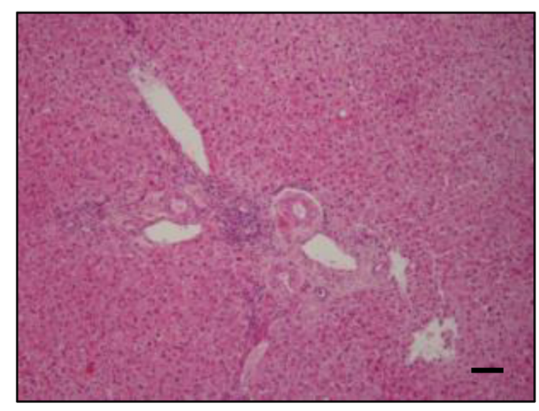

EUG

B

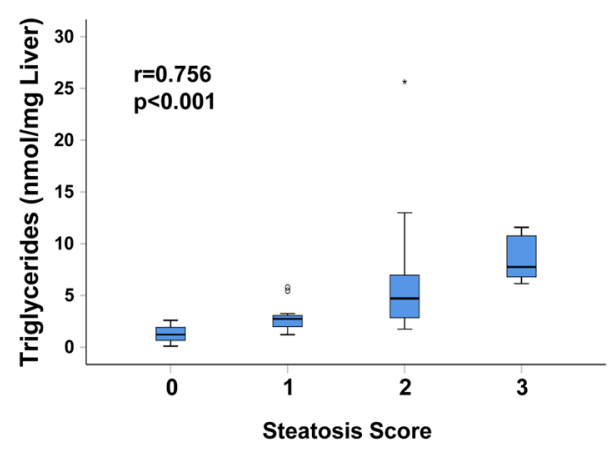

E

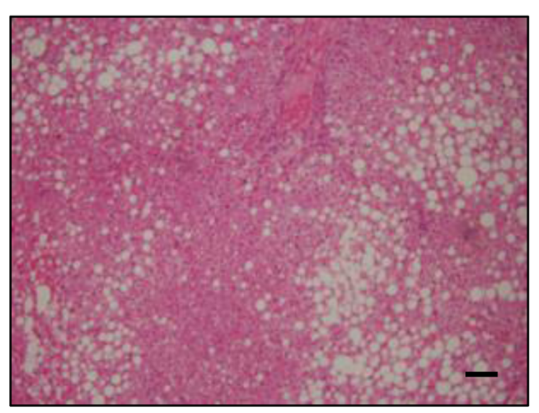

HYPO
C

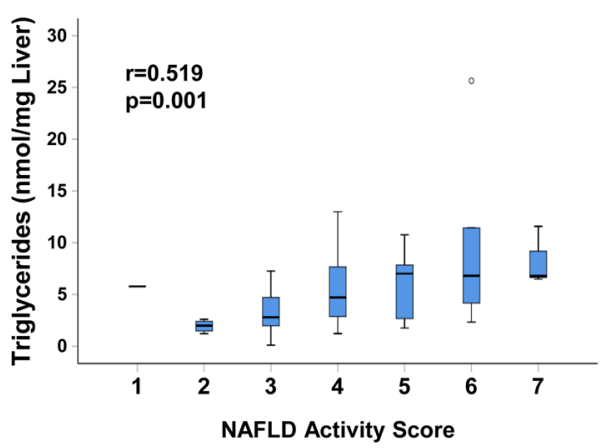

$\mathbf{F}$

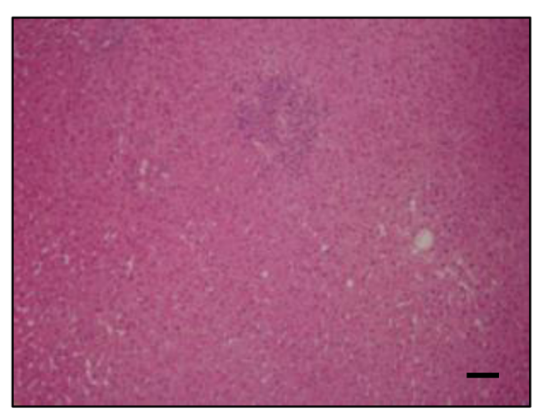

HYPO+TTh
Fig. 4 a Bar graph shows liver triglyceride levels obtained from liver biopsies in all three groups of patients. b, c Display the correlation of liver triglyceride levels with steatosis and NAS scores, respectively. $\mathbf{d}-\mathbf{f}$ Show the H\&E staining of liver sections from eugonadal

hypogonadal subjects (Fig. $6 ; p<0.05$ ). Also lipid catabolism markers such as DIO2 $(p<0.01)$, PRKACA $(p<0.05)$ and PRKACB $(p<0.05)$ were significantly increased in TTh-hypogonadal patients (Fig. 6). The mRNA expression of PDE5 did not show statistically significant differences among the three groups (Fig. 6). We observed a very moderate increase in the mRNA expression of inflammation markers (COX2, GATA3, IL6, IL8, IL12, LOX1, MCP1, ROR $\gamma \mathrm{T}, \mathrm{TBET}$ ) in visceral adipose tissue from hypogonadal patients, a phenomenon that was not affected by TTh (data not shown). Finally, T treatment was associated with a significantly higher mRNA expression of STAMP2, when compared to hypogonadal and eugonadal subjects (Fig. 6).

\section{Effects of testosterone treatment on the expression of genes involved in lipid metabolism and mitochondrial bio-functionality in hPADs}

We next examined the DIM-induced differentiation of human preadipocytes (hPADs) isolated from the different groups after 10 days of culture. Compared to hPADs
(EUG), hypogonadal (HYPO) and hypogonadal subjects treated with testosterone (HYPO $+\mathrm{TTh}$ ), respectively. ${ }^{\mathbf{o}_{p}}<0.05$ vs. Eugonadal; $* p<0.05$ vs. Hypogonadal; Scale bar $100 \mu \mathrm{m}$

obtained from eugonadal patients, hPADs from untreatedhypogonadal patients showed a significant reduction of the mRNA expression of specific markers of brown adipogenesis (BMP7), lipid catabolism (PPAR $\alpha$ ) and insulin signaling (STAMP2) (Fig. 7; $p<0.05$ ) with a parallel increase of genes related to beige/white adipogenesis (BMP4, HOXC9, TBX1; DKK1, FABP4), with PPAR $\gamma 2$ showing an evident, albeit not significant, increase that was normalized by TTh (Fig. 7). On the contrary, in hPADs from T-treated subjects we found a significant increase in the mRNA expression of several genes involved in brown adipogenesis (ADRB3, BMP7, CIDEA, CITED1, UCP1, UCP2), lipid catabolism (PPAR $\alpha$, PRKACA, PRKACB), lipid handling (SNAP23, STX5) and mitochondrial biosynthesis and function (FIS1, FOXC2, MFN2, NDUFB3, NDUFB5, NRF1, SDHB, TFAM), when compared with hPADs derived from hypogonadal patients. The mRNA expression of these genes, in $\mathrm{hPADs}$ originating from the $\mathrm{T}$ treatment group, resulted often even significantly higher than the levels observed in hPADs derived from the eugonadal group (Fig. 7). 

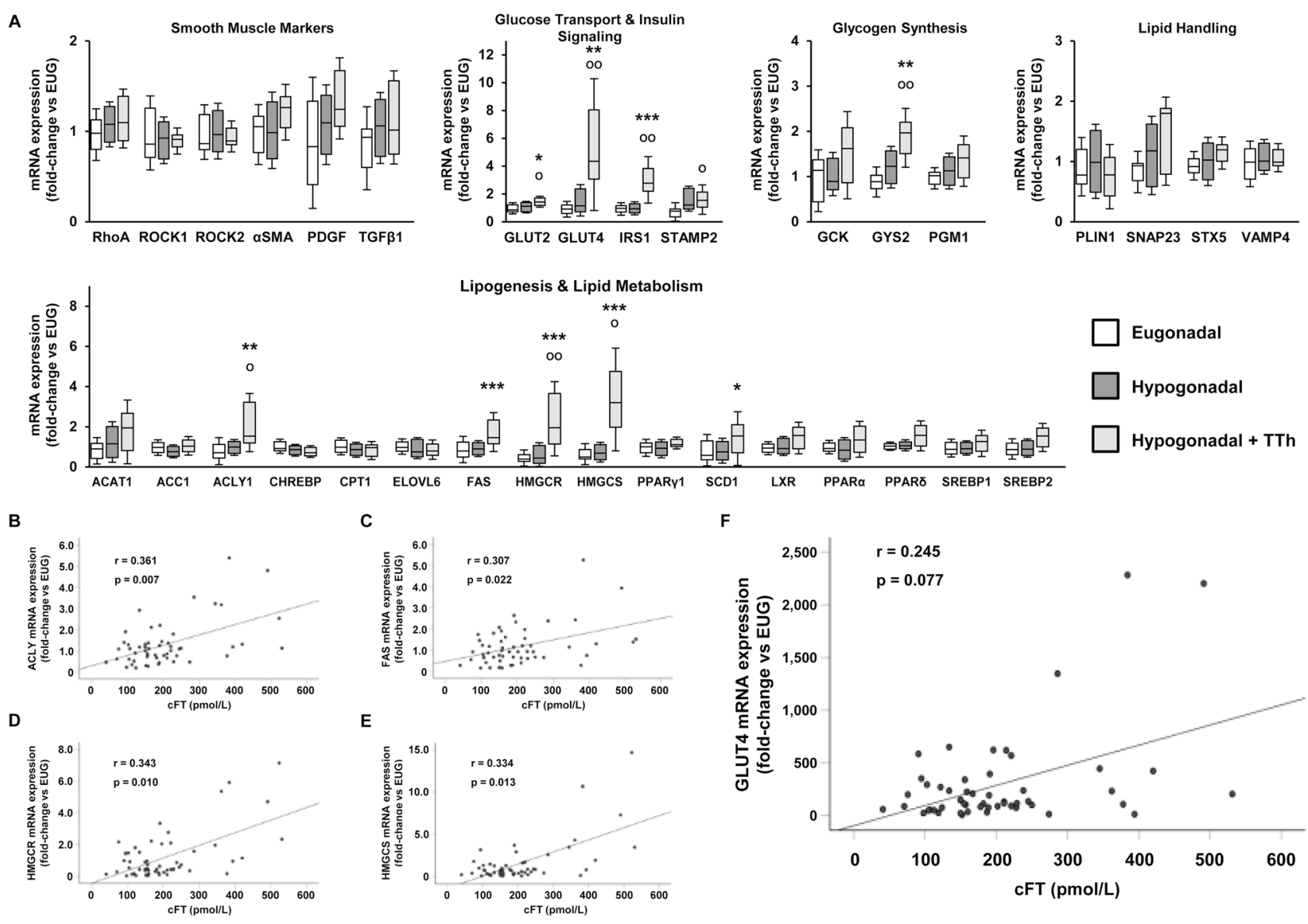

E

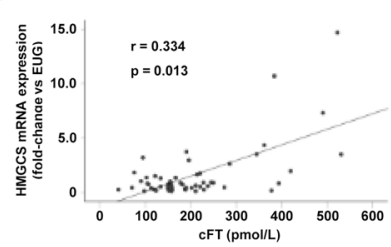

F

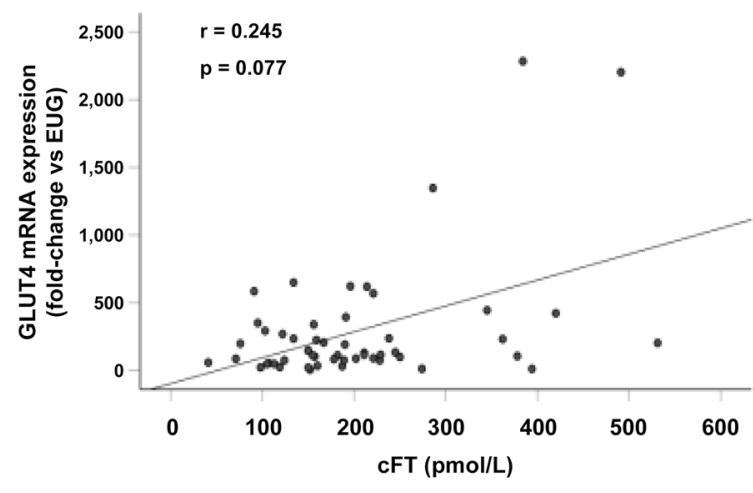

Fig. 5 a Displays the liver tissue relative mRNA expression of smooth muscle/fibrosis markers and genes related to glucose transport, insulin signaling, glycogenesis and lipid handling and metabolism. Data are calculated per the $2^{-\Delta \Delta \mathrm{Ct}}$ comparative method, using the 18S ribosomal RNA subunit as the reference gene for normalization. Results are expressed as fold-change vs. the eugonadal group and are reported in a box plot as interquartiles \pm SEM. Statistical

\section{Testosterone enhances insulin sensitivity in DIM-induced preadipocytes}

In vivo testosterone treatment enhanced the insulin-induced uptake of ${ }^{3} \mathrm{H}$-2-deoxy-D-glucose in hPADs. In DIM-induced hPADs from all groups, insulin increased ${ }^{3} \mathrm{H}$-2-deoxyD-glucose uptake in a dose-dependent manner, with similar $\mathrm{EC}_{50}$ values (shared $\mathrm{EC}_{50}=6.8 \pm 2.3 \mathrm{nM}$ ), but with different maximal effects (Fig. 8 panel a). Indeed, in hPADs from hypogonadal patients, insulin $\mathrm{E}_{\max }$ was significantly reduced compared to eugonadal hPADs (Fig. 8 panel a; $p<0.05)$. Treatment with $\mathrm{T}$ normalized the ability of hPADs to respond to increasing concentrations of insulin (Fig. 8 panel a; $p<0.05$ vs. hypogonadal). Accordingly, the glucose uptake AUC showed a positive correlation with testosterone levels (Fig. 8 panel b; $r=0.431 ; p=0.006$ ). analysis was performed using Kruskal-Wallis and Mann-Whitney tests. b-f show the correlations between cFT and ACLY, FAS, HMGCR, HMGCS and GLUT4 liver mRNA expression, respectively. (Eugonadal, $n=15$; Hypogonadal, $n=26$; Hypogonadal + TTh, $n=15) .{ }^{\circ} p<0.05,{ }^{\circ 0} p<0.01$ vs. Eugonadal; $* p<0.05, * * p<0.01$, $* * * p<0.001$ vs. Hypogonadal

\section{Treatment with testosterone enhances mitochondrial function and preserves their ultrastructure}

To address the mechanisms underlying testosterone-induced effects, we studied the mitochondrial function in hPADs using MitoTracker, a mitochondria-targeted fluorescent probe. Cells with similar shapes were chosen and time-lapse microscopic imaging was used to assess mitochondrial dynamics (Fig. 9 panels a-c). Computer-assisted measurement of mitochondria length in hPADs is reported in Fig. 9 panel d. Mitochondria in eugonadal hPADs showed heterogeneity in shape and length, with small and elongating mitochondria (Fig. 9 panel a), resulting in a dynamic behavior and a wide length distribution (Fig. 9 panel d). In hPADs from hypogonadal patients, mitochondria appeared randomly dispersed, fragmented (Fig. 9 panel b) and immotile, with less elongated mitochondrial 
Table 4 Association between AR mRNA and the expression of target genes related to lipid metabolism, lipid handling, glycogen synthesis, glucose transport and insulin-signaling in the liver

\begin{tabular}{|c|c|c|}
\hline AR mRNA expression & $r$ & $p$ \\
\hline \multicolumn{3}{|c|}{ Lipid metabolism-related genes } \\
\hline ACAT1 & 0.812 & 0.000 \\
\hline $\mathrm{ACC} 1$ & 0.271 & 0.043 \\
\hline ACLY1 & 0.674 & 0.000 \\
\hline ChREBP & -0.291 & 0.030 \\
\hline CPT1 & 0.028 & 0.837 \\
\hline ELOVL6 & 0.138 & 0.309 \\
\hline FAS & 0.440 & 0.001 \\
\hline HMGCR & 0.656 & 0.000 \\
\hline HMGCS & 0.643 & 0.000 \\
\hline LXR & 0.742 & 0.000 \\
\hline $\operatorname{PPAR} \alpha$ & 0.792 & 0.000 \\
\hline PPAR $\delta$ & 0.722 & 0.000 \\
\hline $\operatorname{PPAR} \gamma$ & 0.660 & 0.000 \\
\hline SCD1 & 0.612 & 0.000 \\
\hline SREBF1 & 0.589 & 0.000 \\
\hline SREBF2 & 0.692 & 0.000 \\
\hline \multicolumn{3}{|c|}{ Lipid handling-related genes } \\
\hline PLIN & 0.398 & 0.002 \\
\hline SNAP23 & 0.673 & 0.000 \\
\hline STX5 & 0.708 & 0.000 \\
\hline VAMP4 & 0.350 & 0.009 \\
\hline \multicolumn{3}{|c|}{ Glycogen synthesis-related genes } \\
\hline GCK & 0.145 & 0.338 \\
\hline GYS2 & 0.420 & 0.003 \\
\hline PGM1 & 0.637 & 0.000 \\
\hline \multicolumn{3}{|c|}{ Glucose Transport- and Insulin signaling-related genes } \\
\hline GLUT2 & 0.611 & 0.000 \\
\hline GLUT4 & 0.660 & 0.000 \\
\hline IRS1 & 0.522 & 0.000 \\
\hline STAMP2 & 0.288 & 0.035 \\
\hline
\end{tabular}

Correlations coefficients $(r)$ and level of significance $(p)$ are derived from univariate analysis

network and a lower average length (Fig. 9 panel d; $p<0.01$ vs. eugonadal). Interestingly, the mitochondrial networks of hPADs from the T-treated group were continuously undergoing mitochondrial fission (fragmentation or division) and fusion (rejoining), with rapid changing in shape and length (Fig. 9 panel c), with an increased average length compared to both hypogonadal and eugonadal samples (Fig. 9 panel d; both $p<0.0001$ ).

\section{Effects of testosterone treatment on mitochondrial superoxide generation and oxygen consumption}

Time-dependent accumulation of dihydroethidium (DHE)derived fluorescence was studied as a surrogate marker of spontaneous superoxide production in hPADs (Fig. 10 panel a). Eugonadal hPADs did not show any DHE-derived fluorescence accumulation over time (sequential $30 \mathrm{~s}$ images; Fig. 10 panel a). Conversely, a time-dependent evident increase in superoxide generation was observed in hPADs from hypogonadal patients (sequential $30 \mathrm{~s}$ images; Fig. 10 panel a), whilst $\mathrm{T}$ treatment markedly reduced superoxide production (sequential $30 \mathrm{~s}$ images; Fig. 10 panel a). Quantification of fluorescence intensity changes over time (Fig. 10 panel $\mathrm{b}$ ) also indicated that $\mathrm{T}$ treatment significantly reduced superoxide accumulation observed in untreated-hypogonadal subjects, even significantly below eugonadal level. Figure 10 panel $\mathrm{c}$ shows a higher magnification of DHE-derived fluorescence in each group.

To assess the mitochondrial activity, we next quantified oxygen consumption in hPADs isolated from each experimental group. The hypogonadal group showed a significant reduction (Fig. 10 panel d; $p<0.05$ ) of oxygen consumption compared to eugonadal subjects, whereas testosterone treatment significantly increased the $\mathrm{O}_{2}$ consumption levels, compared to hypogonadal patients $(p<0.05)$, restoring the values up to eugonadal levels (Fig. 10 panel d).

\section{Discussion}

The study is the first to demonstrate that in vivo treatment with the long-lasting $\mathrm{T}$ preparation $\mathrm{T}$ undecanoate in symptomatic hypogonadal obese patients is associated with less severe NASH and visceral adipose tissue dysfunction as compared to untreated-hypogonadal ones. Liver biopsies from T-treated hypogonadal patients showed significantly lower intrahepatic triglyceride content, macrovesicular lipid accumulation and NAS score for steatosis, as compared to untreated-hypogonadal subjects. Accordingly, the clinical and biochemical algorithm which reflects fatty liver was also significantly reduced in TTh-treated hypogonadal patients over time, as compared to untreated-hypogonadal ones. However, the most remarkable results emerge from the experiments in differentiating preadipocytes isolated from human visceral adipose tissue samples of the different treatment groups (eugonadal, TTh-hypogonadal and untreatedhypogonadal subjects). In this large set of experiments, we demonstrated that preadipocytes from TTh patients showed a metabolically healthy phenotype as evidenced by a significantly healthier mitochondrial function, along with a higher insulin sensitivity and oxygen consumption paralleled by a lower superoxide accumulation. Preadipocytes from TThhypogonadal subjects also showed a higher expression of all the genes related to mitochondrial function, beige-brown adipogenesis, insulin signaling, and lipid metabolism, as compared to those from untreated-hypogonadal ones. These cross-sectional data derived from liver and fat biopsies were 

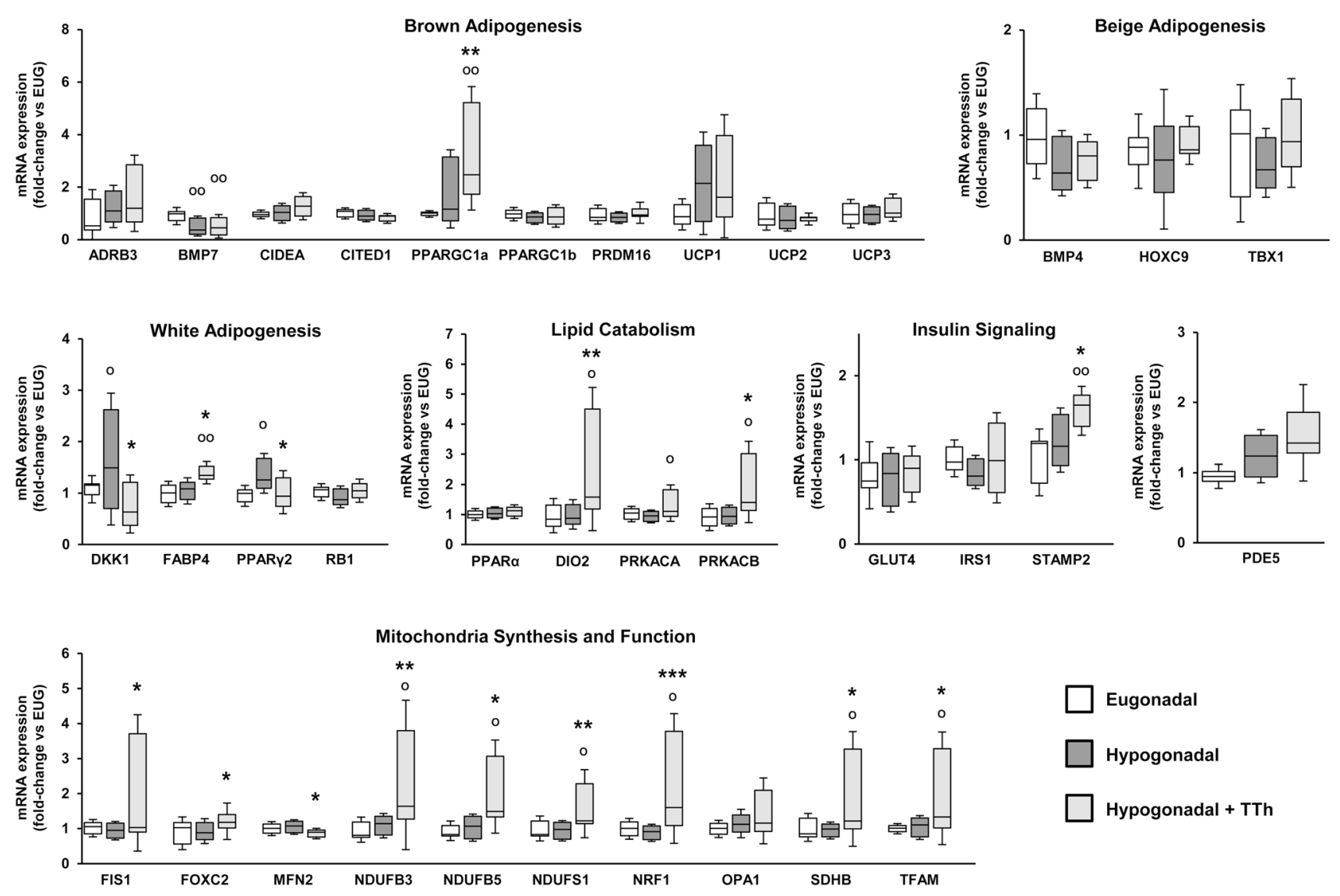

Fig. 6 Visceral adipose tissue relative mRNA expression of genes related to brown, beige and white adipogenesis, lipid catabolism, insulin signaling and mitochondrial life cycle. Data are calculated per the $2^{-\Delta \Delta \mathrm{Ct}}$ comparative method, using the $18 \mathrm{~S}$ ribosomal RNA subunit as the reference gene for normalization. Results are expressed as fold-change vs. the eugonadal group and are reported in a box plot as interquartiles \pm SEM. Statistical analysis was performed using Kruskal-Wallis and Mann-Whitney tests. (Eugonadal, $n=15$; Hypogonadal, $n=37$; Hypogonadal+TTh, $n=15) .{ }^{\mathbf{o}_{p}}<0.05,{ }^{\text {oo }} p<0.01$ vs. Eugonadal; $* p<0.05, * * p<0.01, * * * p<0.001$ vs. Hypogonadal substantiated further by prospective data on biochemical and metabolic parameters. TTh significantly reduced serum cholesterol levels over time (pre-surgery vs. baseline visit), whilst a significant increase with time of triglycerides and transaminases along with a decrease in insulin serum levels (despite higher fasting glucose) was observed in untreated, but not in TTh-treated, hypogonadal subjects. Therefore, our findings further support pre-existing high-quality evidence that TTh induced a range of beneficial metabolic effects in hypogonadal patients [49]. In a recent study by Di Nisio and colleagues [50], a significant deregulation of gene responsiveness to testosterone in obese subcutaneous adipose tissue (SAT) was observed, with testosterone accumulation resulting in lower expression of genes involved in lipolytic and anti-adipogenic pathways, thus suggesting an altered response of dysfunctional fat cells already present in mild obesity. These data corroborate our finding relative to VAT and preadipocytes derived from class III obesity subjects, in which hypogonadism was associated with a decreased expression of genes involved in brown adipogenesis and lipid catabolism. Consistent with these positive metabolic effects of testosterone, a recent meta-analysis of RCTs demonstrated that TTh significantly reduced fasting glycaemia, HOMA index, and fat mass, while increasing lean mass, as compared to placebo [49]. A nonsignificant trend toward reduced total cholesterol and triglyceride level was also induced by TTh [49]. In accordance, a meta-analytic evaluation of observational studies demonstrated that TTh also improves glyco-metabolic control (reduction of HOMA, fasting glycaemia), lipid profile (reduction of triglycerides and total cholesterol level and increased HDL), and body composition (reduction of waist circumference, BMI, body weight and fat mass, and increased lean mass) [27]. A relevant study on a similar population of severely obese hypogonadal men reported an improvement in several cardio-metabolic parameters after 1-year TTh, with only some retained after 24 weeks from withdrawal (i.e. fat, but not lean mass amelioration, was maintained) [51]. Despite these clinically relevant findings, there is limited evidence on the putative biological and molecular mechanisms underlying TTh 

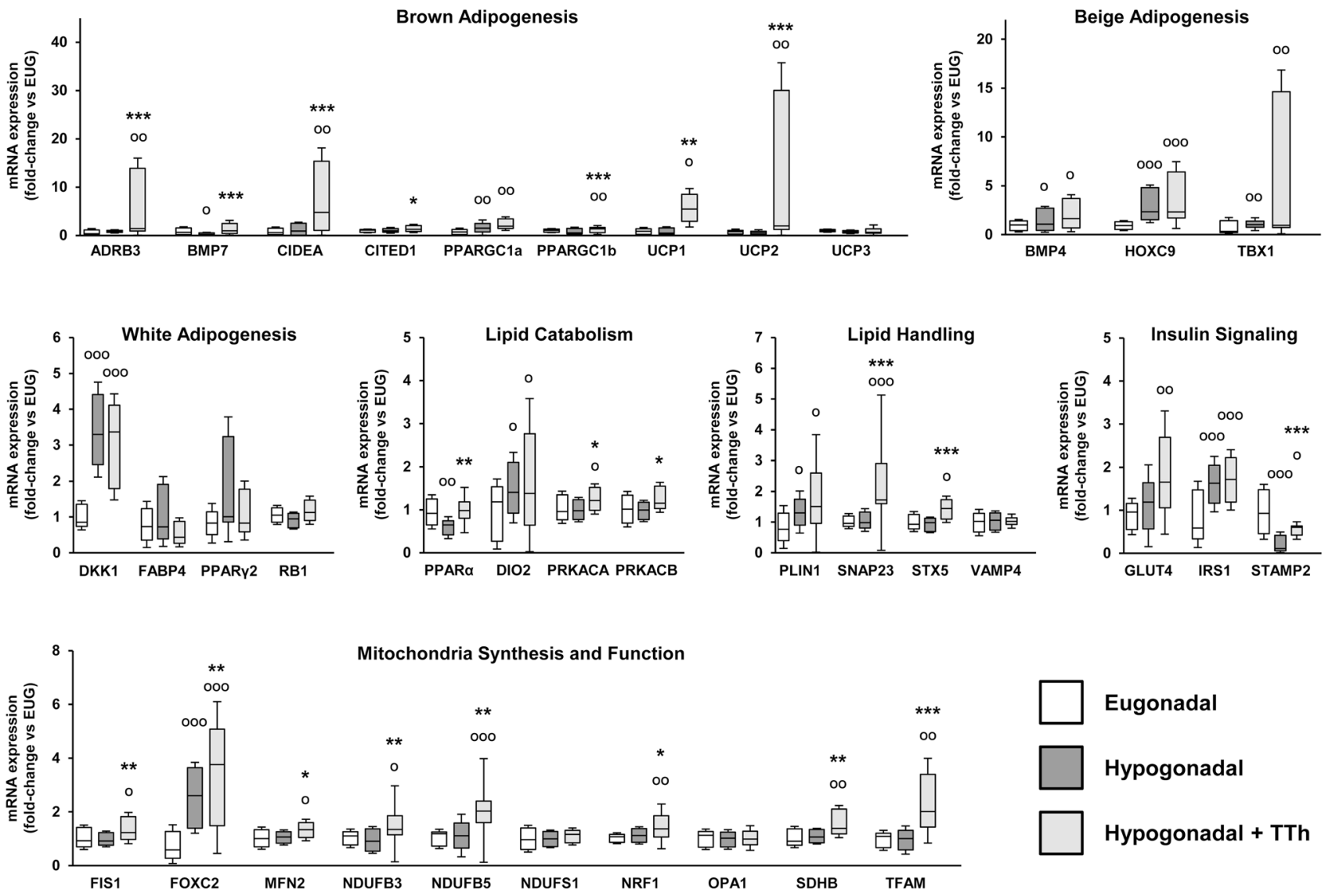

Mitochondria Synthesis and Function

Fig. 7 Human preadipocytes (hPADs) relative mRNA expression of genes related to brown, beige and white adipogenesis, lipid catabolism and handling, insulin signaling and mitochondrial life cycle. Data are calculated per the $2^{-\Delta \Delta \mathrm{Ct}}$ comparative method, using the $18 \mathrm{~S}$ ribosomal RNA subunit as the reference gene for normalization. Results are expressed as fold-change vs. the eugonadal group and are reported in a box plot as interquartiles \pm SEM. Experiments were performed in triplicate using four different hPADs preparations. Statistical analysis was performed using Kruskal-Wallis and Mann-Whitney tests. $\mathbf{O}_{p<0.05}, \mathbf{O O}_{p<0.01}, \mathbf{O O O}_{p<0.001}$ vs. Eugonadal; ${ }^{*} p<0.05$, $* * p<0.01, * * * p<0.001$ vs. Hypogonadal
A

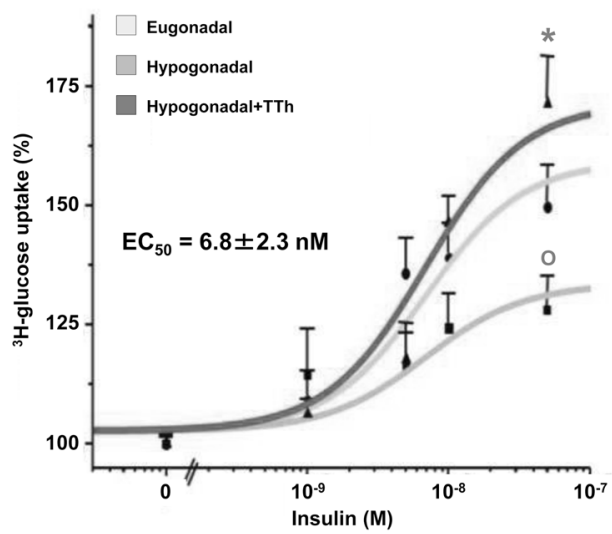

Fig. 8 Panel A shows the insulin dose-dependent ${ }^{3} \mathrm{H}$-2-deoxy-D-glucose uptake in hPADs from all groups after exposure $(30 \mathrm{~min})$ to increasing concentrations of insulin. Results are expressed in percentage over baseline (no insulin) and are reported as mean \pm SEM of four different experiments, each performed in duplicate and using a dif-
B

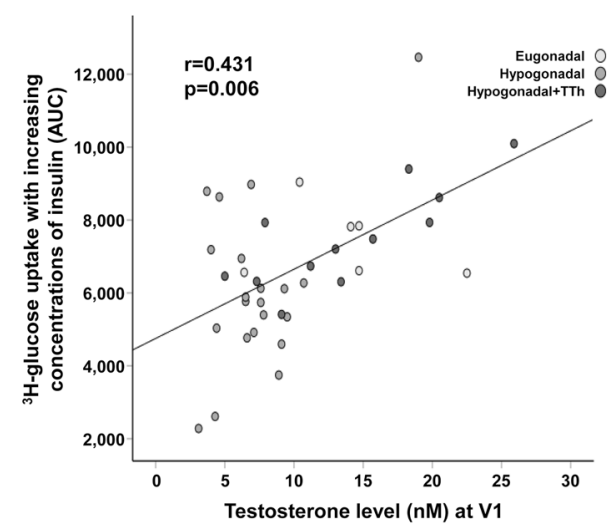

ferent cell preparation per group. b Shows the glucose uptake AUC correlation with total testosterone levels at pre-surgery V1 [AUC: incremental area under the curve of glucose blood level during oral glucose tolerance test (OGTT)]. ${ }^{\mathbf{o}} p<0.05$ vs. Eugonadal; ${ }^{*} p<0.05$ vs. Hypogonadal 
Fig. 9 a-c Show representative time-lapse images of the mitochondrial function in hPADs isolated from all groups of patients, visualized by incubation of the mitochondriatargeted fluorescent probe (MitoTracker staining) and imaged for $3 \mathrm{~min}$. Computerassisted measurement of mitochondria length is reported in $\mathbf{d}$, and respective $p$ values are reported within the panel. For morphometric analysis of mitochondrial length, well-resolved mitochondria in the cell periphery were analyzed by ImageJ software. At least 50 individual mitochondrial structures in at least 10 cells/group were measured to determine mitochondrial length $(\mu \mathrm{m})$ distribution. Data were obtained from three independent experiments
A

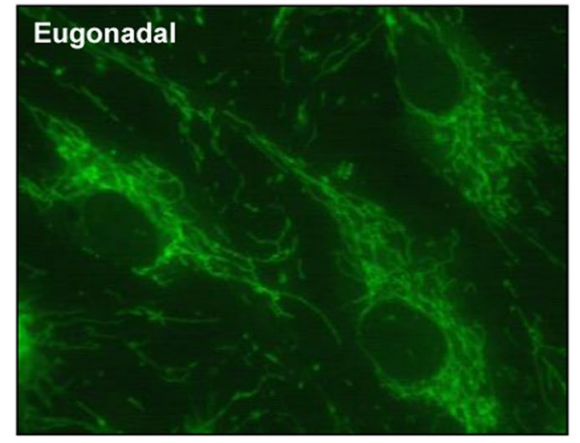

C

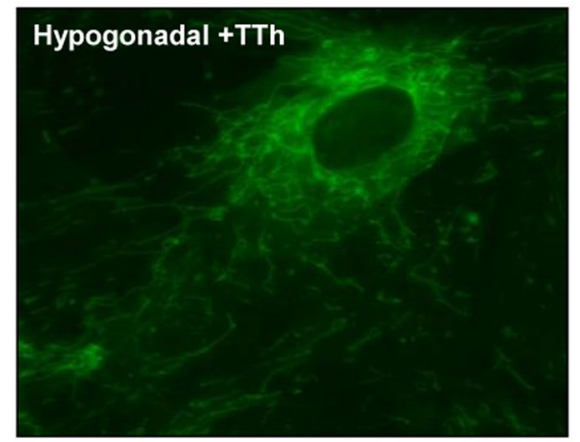

B

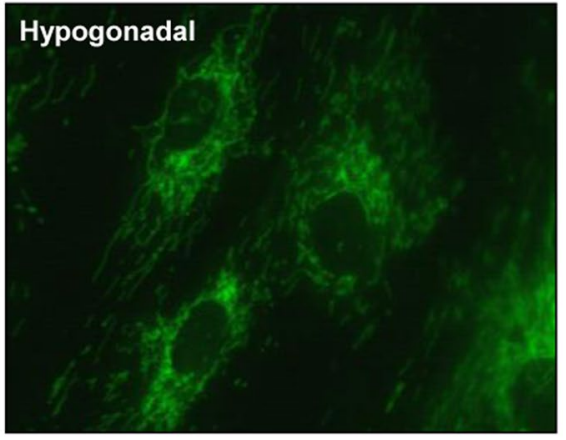

D

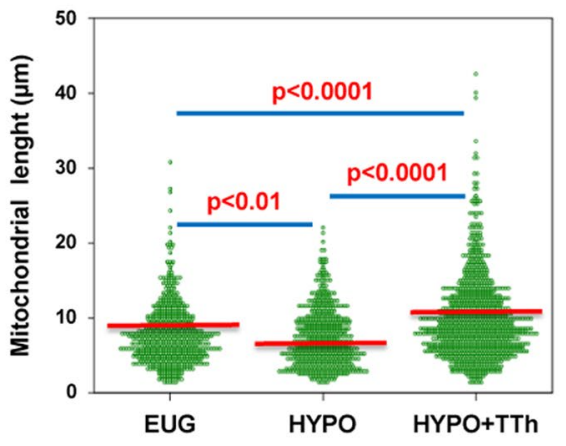

B

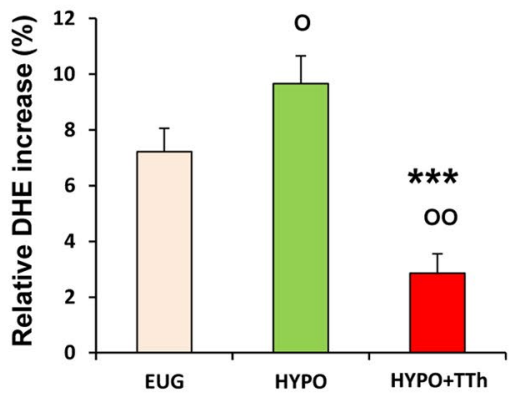

D

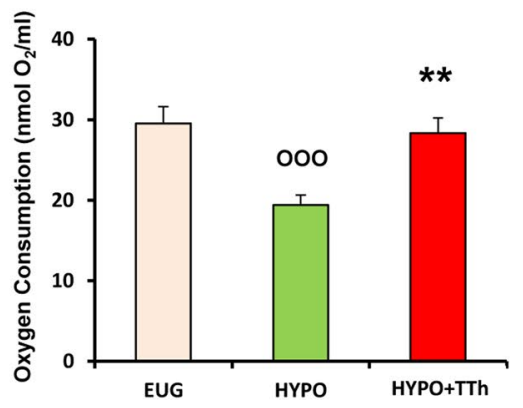

Fig. 10 a Displays representative time-lapse images of hPADs isolated from EUG, HYPO and HYPO + TTh patients, stained with $10 \mu \mathrm{M}$ dihydroethidium (DHE) and imaged for $3 \mathrm{~min}$. b Bar graph shows the changes in integrated fluorescence intensity measured in the nuclei of hPADs during time-lapse imaging. c Shows a higher magnification of DHE-derived fluorescence in each group. Panel D shows the oxygen consumption in hPADs isolated from EUG, HYPO and HYPO + TTh patients after 10 days of spontaneous differentiation. It was measured by the Oxygraph system instrument. The bar graph shows the ratio of oxygen consumption normalized per $\mathrm{mL}$ of cell volume. Data are reported as the mean \pm SEM. of at least three independent experiments. ${ }^{\circ} p<0.05,{ }^{\mathbf{O O}_{p}} p<0.01,{ }^{\text {Ooo }} p<0.001$ vs. Eugonadal; **p $<0.01, * * * p<0.001$ vs. Hypogonadal 
metabolic effects. In this context, the key advantage of the present study design is that it allowed us to explore, not only the systemic, but also the direct, local (within liver and adipose tissue) impact of TTh in severely obese patients, by analyzing and comparing tissue samples collected during the surgical procedure from the three different study arms (eugonadal, T-untreated hypogonadal and T-treated hypogonadal). Interestingly, from adipose tissue samples, we were also able to isolate and differentiate preadipocytes, whose dysfunction has a central role in driving insulin resistance [52]. One of the most intriguing findings was that preadipocytes isolated from TTh subjects showed significantly improved mitochondrial morpho-functional features, as compared to those form untreated- hypogonadal subjects. Mitochondria dysfunctions are nowadays considered as the major underlying driver of several metabolic diseases [53, 54]. Mitochondria constantly undergo fusion and division processes to form a tubular network, which is crucial for health in most eukaryotic cells $[55,56]$. In unhealthy cells, division (fission) becomes predominant and the mitochondrial network fragments, thus reducing energy efficiency, ATP production and fitness to respond to environmental stress buffering reactive oxygen species (ROS) [57-62]. Accordingly, mitochondria in differentiating preadipocytes from untreated-hypogonadal subjects were small, immobile and highly fragmented with reduced networking, oxygen consumption and increased superoxide formation. In contrast, preadipocytes from T-treated hypogonadal patients showed increased mitochondria dynamics and interconnectivity, coupled with increased oxygen consumption and reduced superoxide content. A significantly higher mRNA expression level of mitochondrial biogenesis (NRF1, TFAM), networking (MFN2, FIS1) and function (NDUFB3, NDFUB5, SDHB, FOXC2) markers was also observed in preadipocytes from TTh-hypogonadal patients as compared to untreated-hypogonadal ones. Interestingly, in a rodent model, synergistic activation of two of these markers, namely TFAM and FOXC2, enhanced adipose tissue expression of core proteins of mitochondrial fusion (MFN1, MFN2, and OPA1) consequently leading to a lean and insulin-sensitive phenotype [63-66]. Noteworthy, given that TFAM, one of the most important mitochondrial DNA transcription factors [67-69], contains AR-responsive elements, it is now considered a relevant AR target gene through which testosterone might regulate mitochondrial homeostasis [70]. In line with this evidence, a recent study demonstrated that AR, besides being nuclear, also localizes into mitochondria, where it modulates some of the nongenomic effects of androgens [71]. Therefore, our data further corroborated the positive effects of $\mathrm{T}$ on mitochondrial function. A marked increase of genes related to lipid metabolism/handling (including PPAR $\alpha$, PRKACA, PRAKCB, SNAP23, STX5) and reactive oxygen species removal (such as PPARGC1 $\beta$ ) were also observed in preadipocytes from
T-treated hypogonadal patients. Lipid handling and lipid droplet formation are closely related to mitochondria processes [61]. Essentially, a direct delivery of lipids from lipid droplets into mitochondria represents an efficient way to maintain ROS within physiological levels, thus shielding other cell organelles from lipotoxicity, while ensuring energy supply as well as insulin sensitivity $[11,61,72,73]$. Consistent with this view, we observed a reduced superoxide formation, which was associated with an increase of oxygen consumption and insulin sensitivity in preadipocytes after in vivo TTh. In particular, these preadipocytes demonstrated a significantly improved insulin-stimulated glucose uptake, as compared to preadipocytes from untreated-hypogonadal obese subjects, reaching a level that was even higher than that of eugonadal ones. Noteworthy, the ability of preadipocytes to respond to increasing concentrations of insulin was tightly dependent upon $\mathrm{T}$ level, measured at the pre-surgery visit 1 . The improved metabolic functions of preadipocytes from TTh patients were further supported by a significant increase of all the genes related not only to insulin signaling, mitochondrial biogenesis and lipid handling, but also to brown/beige adipogenesis (ADRB3, CIDEA, CITED1, BMP4, BMP7, HOXC9, TBX1) [74, 75]. In particular, a marked induction of UCP1 and UCP2 was observed in PADs derived from adipose tissue of T-treated hypogonadal obese men. The development of brown/beige adipocytes can be induced in white adipose tissue (WAT), because of a sustained stimulation with cold, B3-adrenergic (ADRB3), peroxisome proliferator-activated receptor $\gamma(\operatorname{PPAR} \gamma)$ agonists, or BMP7. This program is accompanied by induction of uncoupling proteins, especially UCP1, along with an elevated mitochondrial respiration and thermogenesis [76, 77]. In ourstudy, we also found a significant and huge increase of the UCP isoform 2 (UCP2). Interestingly, UCP2 is an ion/ anion transporter located in the mitochondrial inner membrane, with a central function in the regulation of oxidative stress, cellular metabolism and whole energy homeostasis [78]. A reduced UCP2 expression and activity has been linked to obesity-associated metabolic disorders, such as T2DM, hypertension and atherosclerosis [79-82]. In hPADs collected from TTh men, we also found a concomitant increase of crucial factors (e.g. DKK1, DIO2) for adipose tissue differentiation and the maintenance of adipocyte homeostasis, which allows for the balance between lipolysis and adipogenesis [83]. The mRNA expression of PDE5 in adipose tissue, where it is known to be abundantly expressed [84], did not show significant changes. Finally, the observed increase of UCP1 mRNA expression in VAT from both untreated and treated hypogonadal patients, although not significant, could represent an attempt to counterbalance the potentially reduced UCP1 activity in the hypogonadal phenotype. This phenomenon would find its major efficacy in isolated preadipocytes, which display a significant UCP1 
mRNA expression increase only in the TTh group, although the evaluation of UCP1 phosphorylation, rather than mRNA expression, would provide more useful information with regard to its activity. These observations would merit to be analyzed in further studies, perhaps including specific researches on enzymatic activity in a similar model setting.

The aforementioned observations depict a metabolically healthier phenotype for hPADs collected from T-treated obese hypogonadal subjects, as compared with untreatedhypogonadal men. Our data also corroborated the pivotal role of $\mathrm{T}$ in maintaining the homeostasis of mitochondria, the most energetically active organelles in the eukaryotic cells [85]. Previous studies, both in animal models and in humans, demonstrated that androgens stimulate glucose utilization and ATP production, as well as mitochondrial cytochrome c oxidase activity in muscle [86-88], and in several other tissues and cell types [89-92]. However, to our knowledge, this is the first demonstration that in vivo TTh is associated with a healthier phenotype of human preadipocytes. Accordingly, a significantly increased expression of several genes related to mitochondria biogenesis and function, as well as brown/beige adipogenesis, was also observed in the homogenates of visceral adipose tissue samples from TTh-hypogonadal obese subjects, as compared to those of eugonadal and untreated-hypogonadal ones.

Another striking observation of our study is that untreated hypogonadism was associated with a three-fold higher intrahepatic level of triglycerides (assessed in liver biopsies), as compared to eugonadism. This marked increase was not observed in TTh-subjects, whose levels were comparable to eugonadal ones. It is noteworthy that intrahepatic triglyceride content was closely correlated to the histological score of steatosis and with the NAFLD activity score. The fact that we did not observe a parallel decrease in triglycerides levels in TTh-subjects suggests that liver changes could be considered not as the consequence of lower circulating triglycerides, but indeed as the primum movens of the metabolic actions of TTh. As a result, the reduction in hepatic steatosis may be detectable before its consequences appear systemically. Importantly, TTh was also associated with an increased liver expression of all the genes related to insulin signaling, such as GLUT4, IRS1, STAMP2 [93-95], insulin-independent glucose transport (GLUT2) and genes related to glycogen synthesis (of note, glycogen synthase 2, GYS2), and intrahepatic lipid handling. The data relative to the increased expression of GYS2 are substantiated by previous results showing that testosterone replacement favored glycogen synthesis in the skeletal muscle in animal models [96]. Liver from TTh-hypogonadal subjects showed a significant upregulation of FAS, the rate-limiting enzyme in the fatty acid biosynthesis and HMGCs, a catalytic enzyme of ketogenesis that provides lipid-derived energy. Noteworthy, the liver specific FAS knockout aggravates hepatic steatosis, thus suggesting that FAS has a prominent protective effect in the liver [97, 98].

SCD1, an enzyme catalyzing the synthesis of oleate, was also increased in the TTh group, as compared to the untreated one. SCD1 is involved in carbohydrateinduced activation of FAS and other lipogenic enzymes, and recently proposed as a potential therapeutic target to control obesity and the progression of related metabolic diseases including hepatic steatosis [99]. Therefore, the SCD1 mRNA increase in a context of histologically- and biochemically-proven intrahepatic lipid reduction, as observed in T-treated subjects, should be interpreted cautiously. It is plausible that its mRNA increase, in this context, represents a compensatory mechanism in response to a general reduction of liver lipogenesis, rather than a marker of an increased fatty acid formation occurring upon TTh. In line with this interpretation, mRNA expression level of several genes related to liver lipid handling, metabolism and $\beta$-oxidation showed significant positive correlations with calculated free $\mathrm{T}$, as assessed at the pre-surgery visit. The vast majority of these genes were also closely associated with AR mRNA expression. More importantly, histological total NAS score, as well as the subscores related to steatosis and inflammation within the liver, decreased as a function of calculated free $\mathrm{T}$ level at the pre-surgery visit. TTh-hypogonadal subjects showed also a significant reduction of fatty liver index (FLI) and total cholesterol level overtime. In particular, fatty liver index (FLI) — calculated by a specific algorithm based on BMI, waist circumference, triglycerides and yGT-is recognized as an accurate predicting parameter of histologically proven fatty liver [43]. Therefore, given that our main findings are based on differences among treatment groups as assessed within surgical samples, the significant change over time of FLI further strengthened the suggested beneficial effect of TTh on the liver. An association between lower levels of total $\mathrm{T}$ and the development of NAFLD has already been described in the clinical [100-102] and preclinical setting [31, 103-105]. A significant improvement of non-alcoholic liver steatosis upon treatment of hypogonadal elderly men with parenteral $\mathrm{T}$ undecanoate has already been reported $[32,33,106]$. However, having a liver biopsy collected from patients receiving TTh before the surgical procedure, which demonstrated a significant reduction of liver abnormalities, is one of the main strengths of our study.

In contrast to earlier findings [27], we did not find any significant differences between TTh and untreated-hypogonadal subjects in terms of BMI, or glyco-metabolic indices. These discrepancies might be attributed to the shorter therapy duration of our study, as compared to the previous observational trials [27]. Indeed Corona and co-workers found that the 
strength of the beneficial effects of TTh on weight increased as a function of trial duration. To make an example, body weight showed a significant reduction after 24 months of TTh, with an estimated loss of $-3.50[-5.21 ;-1.80] \mathrm{kg}$ [27]. Our observational study was designed to evaluate the effect of TTh based on the time interval spent on the waiting list before the patients received bariatric surgery (roughly 12 months). Another important limitation of the present study lies in the fact that it cannot establish causality due to its observational design. Therefore, it could be hypothesized that men in the eugonadal and hypogonadal (asymptomatic) untreated groups are healthier than the hypogonadal treated (symptomatic) patients. Hence, it could be hypothesized that men in the hypogonadal untreated group are intrinsically less exposed to the detrimental effects of T deficiency than the investigated treated group, made up of hypogonadal symptomatic patients. This establishes a possible selection bias. However, baseline value of body weight, waist circumference, glycol-lipid parameters and blood pressure of the three groups were not statistically different, therefore minimizing the risk of a baseline better cardio-metabolic profile in the TTh arm. Similarly, other possible confounders, including the prevalence of comorbidities (type 2 Diabetes Mellitus, hypertension, cardiovascular diseases), the use of glucoseand lipid-lowering drugs and of PDE5 inhibitors did not show a significant difference between the three groups. It should also be considered that liver and visceral fat biopsies were performed only at the time of bariatric surgery; therefore, data on hepatic inflammation, steatosis and triglyceride content do not allow for a comparison between post-treatment and baseline. This limitation, due to the invasiveness of tissue sample collection, is, at least partially, overcome by the use of the eugonadal group as the comparator for the analyses on these tissues and cells. Finally, a Magnetic Resonance Imaging (MRI) study of liver at baseline and after TTh or a FibroScan evaluation of hepatic tissue would have add interesting data.

In conclusion, we provide evidence that TTh in hypogonadal symptomatic severely obese patients is associated with a reduced preadipocytes dysfunction through an increase of insulin sensitivity, an improvement in mitochondrial function and lipid handling, eventually leading to their differentiation towards a metabolically healthier phenotype. Similarly, testosterone was associated with reduced hepatic steatosis and intrahepatic content of triglycerides. Randomized clinical trials are warranted to confirm these observations.

Acknowledgments Open access funding provided by Universit $\tilde{A}$ degli Studi di Firenze within the CRUI-CARE Agreement.

Funding The original study on which the present article is based was financially supported by Bayer AG.

\section{Compliance with Ethical Standards}

Conflict of interest FS is a consultant for Bayer AG, manufacturer of testosterone-containing products. EM, PC, CC, IC, SF, TM, AG, ER, LP, MT, EF, BB, ML, GR, MM and LV have nothing to declare.

Ethical approval The study protocol was approved by the local ethics committee (protocol 2013/0006753; Careggi Hospital, Florence, Italy).

Informed consent Informed consent was obtained from all individual participants included in the study.

Open Access This article is licensed under a Creative Commons Attribution 4.0 International License, which permits use, sharing, adaptation, distribution and reproduction in any medium or format, as long as you give appropriate credit to the original author(s) and the source, provide a link to the Creative Commons licence, and indicate if changes were made. The images or other third party material in this article are included in the article's Creative Commons licence, unless indicated otherwise in a credit line to the material. If material is not included in the article's Creative Commons licence and your intended use is not permitted by statutory regulation or exceeds the permitted use, you will need to obtain permission directly from the copyright holder. To view a copy of this licence, visit http://creativecommons.org/licenses/by/4.0/.

\section{References}

1. Bonnard C, Durand A, Peyrol S, Chanseaume E, Chauvin MA, Morio B, Vidal H, Rieusset J (2008) Mitochondrial dysfunction results from oxidative stress in the skeletal muscle of dietinduced insulin-resistant mice. J Clin Investig 118(2):789-800

2. Anderson EJ, Lustig ME, Boyle KE, Woodlief TL, Kane DA, Lin CT, Price JW 3rd, Kang L, Rabinovitch PS, Szeto HH, Houmard JA, Cortright RN, Wasserman DH, Neufer PD (2009) Mitochondrial $\mathrm{H}_{2} \mathrm{O}_{2}$ emission and cellular redox state link excess fat intake to insulin resistance in both rodents and humans. J Clin Investig 119(3):573-581

3. Boudina S, Sena S, Sloan C, Tebbi A, Han YH, O'Neill BT, Cooksey RC, Jones D, Holland WL, McClain DA, Abel ED (2012) Early mitochondrial adaptations in skeletal muscle to diet-induced obesity are strain dependent and determine oxidative stress and energy expenditure but not insulin sensitivity. Endocrinology 153(6):2677-2688

4. Martin SD, Morrison S, Konstantopoulos N, McGee SL (2014) Mitochondrial dysfunction has divergent, cell type-dependent effects on insulin action. Mol Metab 3(4):408-418

5. Ozcan U, Cao Q, Yilmaz E, Lee AH, Iwakoshi NN, Ozdelen E, Tuncman G, Görgün C, Glimcher LH, Hotamisligil GS (2004) Endoplasmic reticulum stress links obesity, insulin action, and type 2 diabetes. Science 306(5695):457-461

6. Mantena SK, King AL, Andringa KK, Eccleston HB, Bailey SM (2008) Mitochondrial dysfunction and oxidative stress in the pathogenesis of alcohol- and obesity-induced fatty liver diseases. Free Radic Biol Med 44(7):1259-1272

7. Maneschi E, Vignozzi L, Morelli A, Mello T, Filippi S, Cellai I, Comeglio P, Sarchielli E, Calcagno A, Mazzanti B, Vettor R, Vannelli GB, Adorini L, Maggi M (2013) FXR activation normalizes insulin sensitivity in visceral preadipocytes of a rabbit model of MetS. J Endocrinol 218(2):215-231

8. Maneschi E, Cellai I, Aversa A, Mello T, Filippi S, Comeglio P, Bani D, Guasti D, Sarchielli E, Salvatore G, Morelli A, Mazzanti 
B, Corcetto F, Corno C, Francomano D, Galli A, Vannelli GB, Lenzi A, Mannucci E, Maggi M, Vignozzi L (2016) Tadalafil reduces visceral adipose tissue accumulation by promoting preadipocytes differentiation towards a metabolically healthy phenotype: studies in rabbits. Mol Cell Endocrinol 424:50-70

9. Liu LF, Craig CM, Tolentino LL, Choi O, Morton J, Rivas H, Cushman SW, Engleman EG, McLaughlin T (2017) Adipose tissue macrophages impair preadipocyte differentiation in humans. PLoS ONE 12(2):e0170728

10. Benador IY, Veliova M, Mahdaviani K, Petcherski A, Wikstrom JD, Assali EA, Acín-Pérez R, Shum M, Oliveira MF, Cinti S, Sztalryd C, Barshop WD, Wohlschlegel JA, Corkey BE, Liesa M, Shirihai OS (2018) Mitochondria bound to lipid droplets have unique bioenergetics, composition, and dynamics that support lipid droplet expansion. Cell Metab 27(4):869-885

11. Bach D, Pich S, Soriano FX, Vega N, Baumgartner B, Oriola J, Daugaard JR, Lloberas J, Camps M, Zierath JR, Rabasa-Lhoret R, Wallberg-Henriksson H, Laville M, Palacín M, Vidal H, Rivera F, Brand M, Zorzano A (2003) Mitofusin-2 determines mitochondrial network architecture and mitochondrial metabolism. A novel regulatory mechanism altered in obesity. J Biol Chem 278(19):17190-17197

12. Comeglio P, Cellai I, Mello T, Filippi S, Maneschi E, Corcetto F, Corno C, Sarchielli E, Morelli A, Rapizzi E, Bani D, Guasti D, Vannelli GB, Galli A, Adorini L, Maggi M, Vignozzi L (2018) INT-767 prevents NASH and promotes visceral fat brown adipogenesis and mitochondrial function. J Endocrinol 238(2):107-127

13. Musso G, Gambino R, Bo S, Uberti B, Biroli G, Pagano G, Cassader M (2008) Should nonalcoholic fatty liver disease be included in the definition of metabolic syndrome? A crosssectional comparison with Adult Treatment Panel III criteria in non-obese nondiabetic subjects. Diabetes Care 31(3):562-568

14. Byrne CD, Targher G (2015) NAFLD: a multisystem disease. J Hepatol 62(1S):S47-S64

15. Corona G, Vignozzi L, Sforza A, Mannucci E, Maggi M (2015) Obesity and late-onset hypogonadism. Mol Cell Endocrinol 418(2):120-133

16. Rastrelli G, Carter EL, Ahern T, Finn JD, Antonio L, O'Neill TW, Bartfai G, Casanueva FF, Forti G, Keevil B, Maggi M, Giwercman A, Han TS, Huhtaniemi IT, Kula K, Lean ME, Pendleton N, Punab M, Vanderschueren D, Wu FC, EMAS Study Group (2015) Development of and recovery from secondary hypogonadism in aging men: prospective results from the EMAS. J Clin Endocrinol Metab 100(8):3172-3182

17. Anaissie J, Roberts NH, Wang P, Yafi F (2017) Testosterone replacement therapy and components of the metabolic syndrome. Sex Med Rev 5(2):200-210

18. Filippi S, Vignozzi L, Morelli A, Chavalmane AK, Sarchielli E, Fibbi B, Saad F, Sandner P, Ruggiano P, Vannelli GB, Mannucci E, Maggi M (2009) Testosterone partially ameliorates metabolic profile and erectile responsiveness to PDE5 inhibitors in an animal model of male metabolic syndrome. J Sex Med 6:3274-3288

19. Morelli A, Filippi S, Comeglio P, Sarchielli E, Cellai I, Pallecchi M, Bartolucci G, Danza G, Rastrelli G, Corno C, Guarnieri G, Fuochi E, Vignozzi L, Maggi M (2019) Physical activity counteracts metabolic syndrome-induced hypogonadotropic hypogonadism and erectile dysfunction in the rabbit. Am J Physiol Endocrinol Metab 316(3):E519-E535

20. Kapoor D, Goodwin E, Channer KS, Jones TH (2006) Testosterone replacement therapy improves insulin resistance, glycaemic control, visceral adiposity and hypercholesterolaemia in hypogonadal men with type 2 diabetes. Eur J Endocrinol 154(6):899-906

21. Jones TH, Arver S, Behre HM, Buvat J, Meuleman E, Moncada I, Morales AM, Volterrani M, Yellowlees A, Howell JD, Channer
KS, TIMES2 Investigators (2011) Testosterone replacement in hypogonadal men with type 2 diabetes and/or metabolic syndrome (the TIMES2 study). Diabetes Care 34(4):828-837

22. Hackett G, Cole N, Bhartia M, Kennedy D, Raju J, Wilkinson P, Saghir A, Blast Study Group (2014) The response to testosterone undecanoate in men with type 2 diabetes is dependent on achieving threshold serum levels (the BLAST study). Int J Clin Pract 68(2):203-215

23. Magnussen LV, Glintborg D, Hermann P, Hougaard DM, Højlund K, Andersen M (2016) Effect of testosterone on insulin sensitivity, oxidative metabolism and body composition in aging men with type 2 diabetes on metformin monotherapy. Diabetes Obes Metab 18(10):980-989

24. Mohler ER 3rd, Ellenberg SS, Lewis CE, Wenger NK, Budoff MJ, Lewis MR, Barrett-Connor E, Swerdloff RS, StephensShields A, Bhasin S, Cauley JA, Crandall JP, Cunningham GR, Ensrud KE, Gill TM, Matsumoto AM, Molitch ME, Pahor M, Preston PE, Hou X, Cifelli D, Snyder PJ (2018) The effect of testosterone on cardiovascular biomarkers in the testosterone trials. J Clin Endocrinol Metab 103(2):681-688

25. Haider A, Yassin A, Haider KS, Doros G, Saad F, Rosano GM (2016) Men with testosterone deficiency and a history of cardiovascular diseases benefit from long-term testosterone therapy: observational, real-life data from a registry study. Vasc Health Risk Manag 12:251-261

26. Saad F, Yassin A, Doros G, Haider A (2016) Effects of longterm treatment with testosterone on weight and waist size in 411 hypogonadal men with obesity classes I-III: observational data from two registry studies. Int J Obes (Lond) 40(1):162-170

27. Corona G, Giagulli VA, Maseroli E, Vignozzi L, Aversa A, Zitzmann M, Saad F, Mannucci E, Maggi M (2016) Testosterone supplementation and body composition: results from a meta-analysis of observational studies. J Endocrinol Invest 39(9):967-981

28. Vignozzi L, Morelli A, Filippi S, Comeglio P, Chavalmane AK, Marchetta M, Toce M, Yehiely-Cohen R, Vannelli GB, Adorini L, Maggi M (2011) Farnesoid X receptor activation improves erectile function in animal models of metabolic syndrome and diabetes. J Sex Med 8(1):57-77

29. Maneschi E, Morelli A, Filippi S, Cellai I, Comeglio P, Mazzanti B, Mello T, Calcagno A, Sarchielli E, Vignozzi L, Saad F, Vettor R, Vannelli GB, Maggi M (2012) Testosterone treatment improves metabolic syndrome induced adipose tissue derangements. J Endocrinol 215(3):347-362

30. Kelly DM, Nettleship JE, Akhtar S, Muraleedharan V, Sellers DJ, Brooke JC, McLaren DS, Channer KS, Jones TH (2014) Testosterone suppresses the expression of regulatory enzymes of fatty acid synthesis and protects against hepatic steatosis in cholesterol-fed androgen deficient mice. Life Sci 109(2):95-103

31. Vignozzi L, Filippi S, Comeglio P, Cellai I, Sarchielli E, Morelli A, Rastrelli G, Maneschi E, Galli A, Vannelli GB, Saad F, Mannucci E, Adorini L, Maggi M (2014) Nonalcoholic steatohepatitis as a novel player in metabolic syndrome-induced erectile dysfunction: an experimental study in the rabbit. Mol Cell Endocrinol 384(1-2):143-154

32. Haider A, Gooren LJ, Padungtod P, Saad F (2010) Improvement of the metabolic syndrome and of non-alcoholic liver steatosis upon treatment of hypogonadal elderly men with parenteral testosterone undecanoate. Exp Clin Endocrinol Diabetes 118(3):167-171

33. Hoyos CM, Yee BJ, Phillips CL, Machan EA, Grunstein RR, Liu PY (2012) Body compositional and cardiometabolic effects of testosterone therapy in obese men with severe obstructive sleep apnoea: a randomised placebo-controlled trial. Eur J Endocrinol 167(4):531-541 
34. McVary KT, Roehrborn CG, Avins AL, Barry MJ, Bruskewitz RC, Donnell RF, Foster HE Jr, Gonzalez CM, Kaplan SA, Penson DF, Ulchaker JC, Wei JT (2011) Update on AUA guideline on the management of benign prostatic hyperplasia. J Urol 185:1793-1803

35. Wang C, Nieschlag E, Swerdloff R, Behre HM, Hellstrom WJ, Gooren LJ, Kaufman JM, Legros JJ, Lunenfeld B, Morales A, Morley JE, Schulman C, Thompson IM, Weidner W, Wu FC, International Society of Andrology; International Society for the Study of Aging Male; European Association of Urology; European Academy of Andrology; American Society of Andrology (2009) Investigation, treatment, and monitoring of late-onset hypogonadism in males: ISA, ISSAM, EAU, EAA, and ASA recommendations. Eur Urol 55(1):121-130

36. Vermeulen A, Verdonck L, Kaufman JM (1999) A critical evaluation of simple methods for the estimation of free testosterone in serum. J Clin Endocrinol Metab 84:3666-3672

37. Wu FC, Tajar A, Beynon JM, Pye SR, Silman AJ, Finn JD, O'Neill TW, Bartfai G, Casanueva FF, Forti G, Giwercman A, Han TS, Kula K, Lean ME, Pendleton N, Punab M, Boonen S, Vanderschueren D, Labrie F, Huhtaniemi IT, EMAS Group (2010) Identification of late-onset hypogonadism in middle-aged and elderly men. N Engl J Med 363:123-135

38. Heinemann LAJ, Zimmermann T, Vermeulen A, Thiel C, Hummel W (1999) A new 'aging males' symptoms' rating scale. Aging Male 2(2):105-114

39. Corona G, Rastrelli G, Reisman Y, Sforza A, Maggi M (2018) The safety of available treatments of male hypogonadism in organic and functional hypogonadism. Expert Opin Drug Saf 17(3):277-292

40. Heinemann LA, Saad F, Zimmermann T, Novak A, Myon E, Badia X, Potthoff P, T'Sjoen G, Pöllänen P, Goncharow NP, Kim S, Giroudet C (2003) The Aging Males' Symptoms (AMS) scale: update and compilation of international versions. Health Qual Life Outcomes 1:15

41. Daig I, Heinemann LA, Kim S, Leungwattanakij S, Badia X, Myon E, Moore C, Saad F, Potthoff P, Thaido M (2003) The Aging Males' Symptoms (AMS) scale: review of its methodological characteristics. Health Qual Life Outcomes 1:77

42. Lotti F, Maggi M (2015) Ultrasound of the male genital tract in relation to male reproductive health. Hum Reprod Update 21(1):56-83

43. Bedogni G, Bellentani S, Miglioli L, Masutti F, Passalacqua M, Castiglione A, Tiribelli C (2006) The Fatty Liver Index: a simple and accurate predictor of hepatic steatosis in the general population. BMC Gastroenterol 6:33

44. Comeglio P, Filippi S, Sarchielli E, Morelli A, Cellai I, Corcetto F, Corno C, Maneschi E, Pini A, Adorini L, Vannelli GB, Maggi M, Vignozzi L (2017) Anti-fibrotic effects of chronic treatment with the selective FXR agonist obeticholic acid in the bleomycin-induced rat model of pulmonary fibrosis. J Steroid Biochem Mol Biol 168:26-37

45. Livak KJ, Schmittgen TD (2001) Analysis of relative gene expression data using real-time quantitative PCR and the 2(-Delta Delta C(T)) method. Methods 25:402-408

46. Schindelin J, Arganda-Carreras I, Frise E, Kaynig V, Longair M, Pietzsch T, Preibisch S, Rueden C, Saalfeld S, Schmid B, Tinevez JY, White DJ, Hartenstein V, Eliceiri K, Tomancak P, Cardona A (2012) Fiji: an open-source platform for biologicalimage analysis. Nat Methods 9:676-682

47. Rapizzi E, Fucci R, Giannoni E, Canu L, Richter S, Cirri P, Mannelli M (2015) Role of microenvironment on neuroblastoma SK-N-AS SDHB silenced cell metabolism and function. Endocr Relat Cancer 22:409-417

48. DeLean A, Munson PJ, Rodbard D (1978) Simultaneous analysis of families of sigmoidal curves: application to bioassay, radioligand assay, and physiological dose-response curves. Am J Physiol 235:E97-E102

49. Corona G, Giagulli VA, Maseroli E, Vignozzi L, Aversa A, Zitzmann M, Saad F, Mannucci E, Maggi M (2016) Therapy of endocrine disease: Testosterone supplementation and body composition: results from a meta-analysis study. Eur J Endocrinol 174(3):R99-R116

50. Di Nisio A, Sabovic I, De Toni L, Rocca MS, Dall'Acqua S, Azzena B, De Rocco PM, Foresta C (2020) Testosterone is sequestered in dysfunctional adipose tissue, modifying androgen-responsive genes. Int J Obes (Lond) 44(7):1617-1625

51. Francomano D, Bruzziches R, Barbaro G, Lenzi A, Aversa A (2014) Effects of testosterone undecanoate replacement and withdrawal on cardio-metabolic, hormonal and body composition outcomes in severely obese hypogonadal men: a pilot study. J Endocrinol Invest 37(4):401-411

52. Arner E, Westermark PO, Spalding KL, Britton T, Rydén M, Frisén J, Bernard S, Arner P (2010) Adipocyte turnover: relevance to human adipose tissue morphology. Diabetes 59(1):105-109

53. Baker PR 2nd, Friedman JE (2018) Mitochondrial role in the neonatal predisposition to developing nonalcoholic fatty liver disease. J Clin Invest 128(9):3692-3703

54. Yaribeygi H, Atkin SL, Sahebkar A (2019) Mitochondrial dysfunction in diabetes and the regulatory roles of antidiabetic agents on the mitochondrial function. J Cell Physiol 234(6):8402-8410

55. Detmer SA, Chan DC (2007) Functions and dysfunctions of mitochondrial dynamics. Nat Rev Mol Cell Biol 8(11):870-879

56. Otera H, Mihara K (2011) Molecular mechanisms and physiologic functions of mitochondrial dynamics. J Biochem 149(3):241-251

57. Newmeyer DD, Ferguson-Miller S (2003) Mitochondria: releasing power for life and unleashing the machineries of death. Cell 112(4):481-490

58. Suen DF, Norris KL, Youle RJ (2008) Mitochondrial dynamics and apoptosis. Genes Dev 22(12):1577-1590

59. Sebastián D, Hernández-Alvarez MI, Segalés J, Sorianello E, Muñoz JP, Sala D, Waget A, Liesa M, Paz JC, Gopalacharyulu P, Orešič M, Pich S, Burcelin R, Palacín M, Zorzano A (2012) Mitofusin 2 (Mfn2) links mitochondrial and endoplasmic reticulum function with insulin signaling and is essential for normal glucose homeostasis. Proc Natl Acad Sci USA 109(14):5523-5528

60. Liesa M, Shirihai OS (2013) Mitochondrial dynamics in the regulation of nutrient utilization and energy expenditure. Cell Metab 17:491-506

61. Aon MA, Bhatt N, Cortassa SC (2014) Mitochondrial and cellular mechanisms for managing lipid excess. Front Physiol 5:282

62. Schrepfer E, Scorrano L (2016) Mitofusins, from mitochondria to metabolism. Mol Cell 61(5):683-694

63. Toh SY, Gong J, Du G, Li JZ, Yang S, Ye J, Yao H, Zhang Y, Xue B, Li Q, Yang H, Wen Z, Li P (2008) Up-regulation of mitochondrial activity and acquirement of brown adipose tissue-like property in the white adipose tissue of fsp27 deficient mice. PLoS ONE 3(8):e2890

64. Lidell ME, Seifert EL, Westergren R, Heglind M, Gowing A, Sukonina V, Arani Z, Itkonen P, Wallin S, Westberg F, Fernandez-Rodriguez J, Laakso M, Nilsson T, Peng XR, Harper ME, Enerbäck S (2011) The adipocyte-expressed forkhead transcription factor Foxc2 regulates metabolism through altered mitochondrial function. Diabetes 60(2):427-435

65. Gan L, Liu Z, Chen Y, Luo D, Feng F, Liu G, Sun C (2016) $\alpha$-MSH and Foxc2 promote fatty acid oxidation through $\mathrm{C} /$ 
EBP $\beta$ negative transcription in mice adipose tissue. Sci Rep 6:36661

66. Gan L, Liu Z, Feng F, Wu T, Luo D, Hu C, Sun C (2018) Foxc2 coordinates inflammation and browning of white adipose by leptin-STAT3-PRDM16 signal in mice. Int J Obes (Lond) 42(2):252-259

67. Ekstrand MI, Falkenberg M, Rantanen A, Park CB, Gaspari M, Hultenby K, Rustin P, Gustafsson CM, Larsson NG (2004) Mitochondrial transcription factor A regulates mtDNA copy number in mammals. Hum Mol Genet 13(9):935-944

68. Clay Montier LL, Deng JJ, Bai Y (2009) Number matters: control of mammalian mitochondrial DNA copy number. J Genet Genomics 36(3):125-131

69. Taherzadeh-Fard E, Saft C, Akkad DA, Wieczorek S, Haghikia A, Chan A, Epplen JT, Arning L (2011) PGC-1alpha downstream transcription factors NRF-1 and TFAM are genetic modifiers of Huntington disease. Mol Neurodegener 6(1):32

70. Liu C, Ma J, Zhang J, Zhao H, Zhu Y, Qi J, Liu L, Zhu L, Jiang Y, Tang G, Li X, Li M (2019) Testosterone deficiency caused by castration modulates mitochondrial biogenesis through the AR/ PGC1 $\alpha /$ TFAM pathway. Front Genet 10:505

71. Bajpai P, Koc E, Sonpavde G, Singh R, Singh KK (2019) Mitochondrial localization, import, and mitochondrial function of the androgen receptor. J Biol Chem 294(16):6621-6634

72. Toledo FG, Sniderman AD, Kelley DE (2006) Influence of hepatic steatosis (fatty liver) on severity and composition of dyslipidemia in type 2 diabetes. Diabetes Care 29(8):1845-1850

73. Mason RR, Watt MJ (2015) Unraveling the roles of PLIN5: linking cell biology to physiology. Trends Endocrinol Metab 26(3):144-152

74. Lehman JJ, Barger PM, Kovacs A, Saffitz JE, Medeiros DM, Kelly DP (2000) Peroxisome proliferator-activated receptor $\gamma$ coactivator-1 promotes cardiac mitochondrial biogenesis. J Clin Invest 106(7):847-856

75. Austin S, St-Pierre J (2012) PGC1 $\alpha$ and mitochondrial metabolism-emerging concepts and relevance in ageing and neurodegenerative disorders. J Cell Sci 125(21):4963-4971

76. Fedorenko A, Lishko PV, Kirichok Y (2012) Mechanism of fatty-acid-dependent UCP1 uncoupling in brown fat mitochondria. Cell 151(2):400-413

77. Rosen ED, Spiegelman BM (2014) What we talk about when we talk about fat. Cell 156(1-2):20-44

78. Li J, Jiang R, Cong X, Zhao Y (2019) UCP2 gene polymorphisms in obesity and diabetes, and the role of UCP2 in cancer. FEBS Lett 593(18):2525-2534

79. Wang H, Chu WS, Lu T, Hasstedt SJ, Kern PA, Elbein SC (2004) Uncoupling protein-2 polymorphisms in type 2 diabetes, obesity, and insulin secretion. Am J Physiol Endocrinol Metab 286(1):E1-E7

80. Mahadik SR, Lele RD, Saranath D, Seth A, Parikh V (2012) Uncoupling protein-2 (UCP2) gene expression in subcutaneous and omental adipose tissue of Asian Indians: relationship to adiponectin and parameters of metabolic syndrome. Adipocyte 1(2):101-107

81. de Souza BM, Brondani LA, Bouças AP, Sortica DA, Kramer CK, Canani LH, Leitão CB, Crispim D (2013) Associations between UCP1 -3826A/G, UCP2 -866G/A, Ala55Val and Ins/Del, and UCP3 $-55 \mathrm{C} / \mathrm{T}$ polymorphisms and susceptibility to type 2 diabetes mellitus: case-control study and meta-analysis. PLoS ONE 8(1):e54259

82. Qian L, Xu K, Xu X, Gu R, Liu X, Shan S, Yang T (2013) UCP2 -866G/A, Ala55Val and UCP3 -55C/T polymorphisms in association with obesity susceptibility - a meta-analysis study. PLoS ONE 8(4):e58939

83. Schroeder F, Petrescu AD, Huang H, Atshaves BP, McIntosh AL, Martin GG, Hostetler HA, Vespa A, Landrock D, Landrock KK, Payne HR, Kier AB (2008) Role of fatty acid binding proteins and long chain fatty acids in modulating nuclear receptors and gene transcription. Lipids 43(1):1-17

84. Armani A, Marzolla V, Rosano GM, Fabbri A, Caprio M (2011) Phosphodiesterase type 5 (PDE5) in the adipocyte: a novel player in fat metabolism? Trends Endocrinol Metab 22(10):404-411

85. Aversa R, Petrescu RVV, Apicella A, Petrescu FIT (2016) Mitochondria are naturally micro robots - a review. Am J Eng Appl Sci 9(4):991-1002

86. Traish AM, Abdallah B, Yu G (2011) Androgen deficiency and mitochondrial dysfunction: implications for fatigue, muscle dysfunction, insulin resistance, diabetes, and cardiovascular disease. Horm Mol Biol Clin Investig 8(1):431-444

87. Apaiajai N, Chunchai T, Jaiwongkam T, Kerdphoo S, Chattipakorn SC, Chattipakorn N (2018) Testosterone deprivation aggravates left-ventricular dysfunction in male obese insulin-resistant rats via impairing cardiac mitochondrial function and dynamics proteins. Gerontology 64(4):333-343

88. Jensen RC, Christensen LL, Nielsen J, Schrøder HD, Kvorning T, Gejl K, Højlund K, Glintborg D, Andersen M (2018) Mitochondria, glycogen, and lipid droplets in skeletal muscle during testosterone treatment and strength training: a randomized, double-blinded, placebo-controlled trial. Andrology 6(4):547-555

89. Gorgey AS, Khalil RE, Gill R, O'Brien LC, Lavis T, Castillo T, Cifu DX, Savas J, Khan R, Cardozo C, Lesnefsky EJ, Gater DR, Adler RA (2017) Effects of testosterone and evoked resistance exercise after spinal cord injury (TEREX-SCI): study protocol for a randomised controlled trial. BMJ Open 7(4):e014125

90. Rovira-Llopis S, Bañuls C, de Marañon AM, Diaz-Morales N, Jover A, Garzon S, Rocha M, Victor VM, Hernandez-Mijares A (2017) Low testosterone levels are related to oxidative stress, mitochondrial dysfunction and altered subclinical atherosclerotic markers in type 2 diabetic male patients. Free Radic Biol Med 108:155-162

91. Yan W, Kang Y, Ji X, Li S, Li Y, Zhang G, Cui H, Shi G (2017) Testosterone upregulates the expression of mitochondrial ND1 and ND4 and alleviates the oxidative damage to the nigrostriatal dopaminergic system in orchiectomized rats. Oxid Med Cell Longev 2017:1202459

92. Kang J, Jia Z, Ping Y, Liu Z, Yan X, Xing G, Yan W (2018) Testosterone alleviates mitochondrial ROS accumulation and mitochondria-mediated apoptosis in the gastric mucosa of orchiectomized rats. Arch Biochem Biophys 649:53-59

93. Nandi A, Kitamura Y, Kahn CR, Accili D (2004) Mouse models of insulin resistance. Physiol Rev 84:623-647

94. White MF (2002) IRS proteins and the common path to diabetes. Am J Physiol Endocrinol Metab 283(3):E413-E422

95. Yoo SK, Cheong J, Kim HY (2014) STAMPing into Mitochondria. Int J Biol Sci 10(3):321-326

96. Haren MT, Siddiqui AM, Armbrecht HJ, Kevorkian RT, Kim MJ, Haas MJ, Mazza A, Kumar VB, Green M, Banks WA, Morley JE (2011) Testosterone modulates gene expression pathways regulating nutrient accumulation, glucose metabolism and protein turnover in mouse skeletal muscle. Int J Androl 34(1):55-68

97. Chakravarthy MV, Pan Z, Zhu Y, Tordjman K, Schneider JG, Coleman T, Turk J, Semenkovich CF (2005) "New" hepatic fat activates PPARalpha to maintain glucose, lipid, and cholesterol homeostasis. Cell Metab 1(5):309-322

98. Koo SH (2013) Nonalcoholic fatty liver disease: molecular mechanisms for the hepatic steatosis. Clin Mol Hepatol 19(3):210-215

99. Aljohani AM, Syed DN, Ntambi JM (2017) Insights into stearoylCoA desaturase-1 regulation of systemic metabolism. Trends Endocrinol Metab 28(12):831-842

100. Mody A, White D, Kanwal F, Garcia JM (2015) Relevance of low testosterone to non-alcoholic fatty liver disease. Cardiovasc Endocrinol 4(3):83-89 
101. Mintziori G, Poulakos P, Tsametis C, Goulis DG (2017) Hypogonadism and non-alcoholic fatty liver disease. Minerva Endocrinol 42(2): $145-150$

102. Van de Velde F, Bekaert M, Hoorens A, Geerts A, T'Sjoen G, Fiers T, Kaufman JM, Van Nieuwenhove Y, Lapauw B (2019) Histologically proven hepatic steatosis associates with lower testosterone levels in men with obesity. Asian J Androl. https://doi.org/10.4103/ aja.aja_68_19(in press)

103. Lin HY, Yu IC, Wang RS, Chen YT, Liu NC, Altuwaijri S, Hsu CL, Ma WL, Jokinen J, Sparks JD, Yeh S, Chang C (2008) Increased hepatic steatosis and insulin resistance in mice lacking hepatic androgen receptor. Hepatology 47(6):1924-1935

104. Aoki A, Fujitani K, Takagi K, Kimura T, Nagase H, Nakanishi $\mathrm{T}$ (2016) Male hypogonadism causes obesity associated with impairment of hepatic gluconeogenesis in mice. Biol Pharm Bull 39(4):587-592
105. Hussein AMHF, Eid EA, Al Khateeb M (2018) Possible mechanisms underlying fatty liver in a rat model of male hypogonadism: A protective role for testosterone. Steroids 135:21-30

106. Sinclair M, Grossmann M, Hoermann R, Angus PW, Gow PJ (2016) Testosterone therapy increases muscle mass in men with cirrhosis and low testosterone: A randomised controlled trial. J Hepatol 65(5):906-913

Publisher's Note Springer Nature remains neutral with regard to jurisdictional claims in published maps and institutional affiliations. 